\title{
Influencing Factors on the Interface Microhardness of Lightweight Aggregate Concrete Consisting of Glazed Hollow Bead
}

\author{
Gang Ma, Yu Zhang, and Zhu Li \\ College of Architecture and Civil Engineering, Taiyuan University of Technology, Taiyuan 030024, China \\ Correspondence should be addressed to Zhu Li; tyutmg@163.com
}

Received 18 July 2014; Revised 12 August 2014; Accepted 27 August 2014

Academic Editor: Qingrui Zhang

Copyright (C) 2015 Gang Ma et al. This is an open access article distributed under the Creative Commons Attribution License, which permits unrestricted use, distribution, and reproduction in any medium, provided the original work is properly cited.

\begin{abstract}
Lightweight aggregate concrete consisting of glazed hollow bead (GHB) as lightweight aggregate is studied for the influence of nanosilica (NS) content, prewetting time for GHB, water-cement ratio, and curing humidity, on the interface structure between GHB and cement paste. This research analyzed the influences of various factors on the interface zone structure by measuring microhardness (HV) and hydration degree of cement paste (HD) nearby the interface zone $(1 \mathrm{~mm})$ between GHB and cement paste at different periods of aging. Due to the sampling limitation, the interface zone in this test is within $1 \mathrm{~mm}$ away from the surface of lightweight aggregate. The HD of cement paste was determined through chemically combined water (CCW) test. The results were expected to reflect the influence of various factors on the interface zone structure. Results showed that the rational control of the four factors studied could fully mobilize the water absorption and desorption properties of GHB to improve the characteristics of the interfacial transition zone.
\end{abstract}

\section{Introduction}

1.1. Overview. Material's microstructure determines its macroscopic mechanism. The research on microstructure mainly focused on aggregate, cement, and interfacial transition zone between them. In normal concrete, the interfacial transition zones (ITZs) exist between cement paste and aggregate, which have essentially the same components as in cement paste but have largely different structure and properties from the cement paste. This is attributed mostly to the film of water that forms around the aggregate particles. The water-cement ratio in surface bulk phase close to the surface of coarse aggregate is greater than that in surface bulk phase away from the surface of coarse aggregate. Many pores leading to the directional alignment of $\mathrm{Ca}(\mathrm{OH})_{2}$ often become the weakest link in the normal concrete. Likewise, in lightweight aggregate concrete, interfacial transition zone between the lightweight aggregate and cement paste can have strong influence on the macroscopic properties of lightweight aggregate concrete [1].
The mechanical properties, workability, and durability performance are different for the lightweight aggregate concrete and normal concrete. Lightweight aggregate belongs to the porous material, which contains holes with varying dimensions. The environmental conditions, surface morphology, moisture content, and degree of connectivity of holes have a greater influence on the ITZ. Under a load, due to the inconsistent deformation produced by the difference in elastic modulus between the lightweight aggregate and cement paste, the stress concentration is likely to occur in the ITZ. Concrete structure is damaged under the process of connecting action of primary and secondary cracks caused by the microcracks. However, the water absorption and desorption property of the lightweight aggregate can increase the local water to cement ratio of the ITZ and improve the ITZ. Zhang et al. [2,3] proposed a physical model of the ITZ between the lightweight aggregate and cement paste. However, the study lacked systematic research on the influence of various factors on internal curing effect of lightweight aggregate and the influence of 


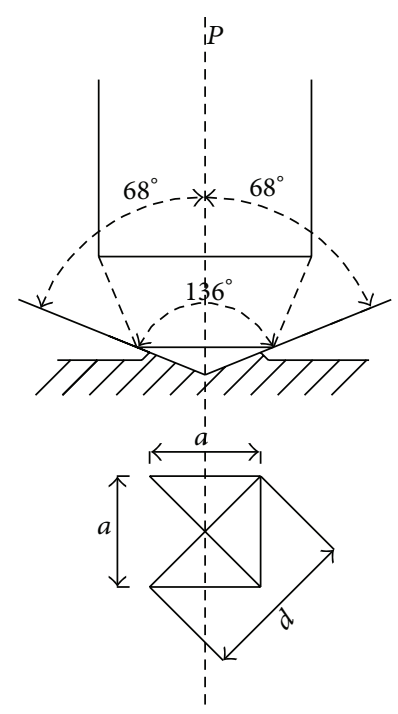

FIGURE 1: Head shape and principle of HV tester.

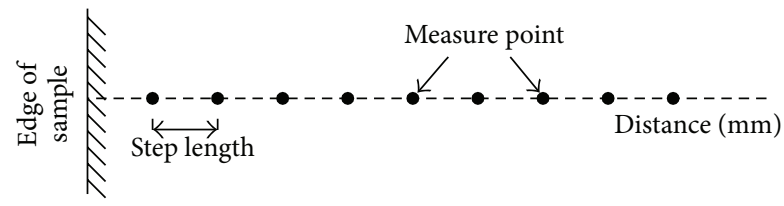

FIGURE 2: Distribution of measuring locations of HV.

mineral admixtures on the structural strength of lightweight aggregate interface [4].

As a new type of lightweight aggregate, the glazed hollow bead (GHB) has the characteristics of lightweight, porous interior and vitreous external surface, and micropumping function that allows water absorption and desorption in cement paste. The lightweight aggregate concrete with GHB as lightweight aggregate has good bearing strength and heat insulation performance. The strength of interface zone between GHB and cement paste has important influence on the macroscopic properties of the lightweight aggregate concrete.

1.2. Interaction Mechanism between Lightweight Aggregate and Cement Paste. Concrete is a multiphase and heterogeneous system. The interface between each phase is an important part of the internal structure of concrete. There is a significant amount of research on the interface between the aggregate and cement paste. The interface interaction mechanism between them includes physical, chemical, and mechanical actions [5]. If the surface of aggregate is smooth and there is no chemical reaction between aggregate and cement paste, the action between aggregate and cement paste is the physical function of Van der Waals force. The interface bonding strength between the aggregate and cement paste is relatively low $[6,7]$. If the chemical reaction of aggregate and cement paste occurs to a certain extent, the aggregate and

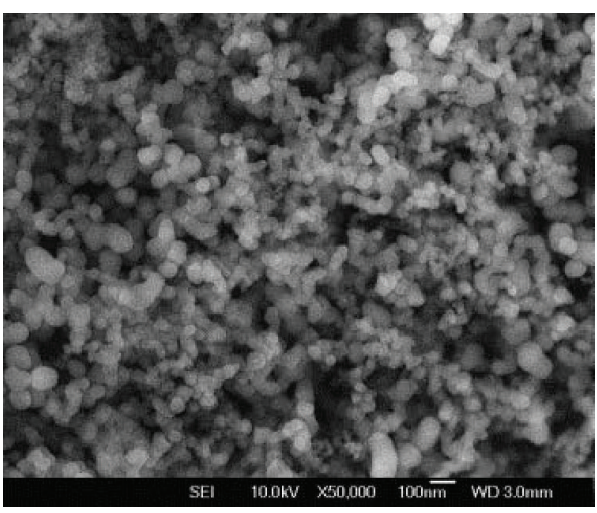

FIgURE 3: The morphology of NS obtained by using SEM.

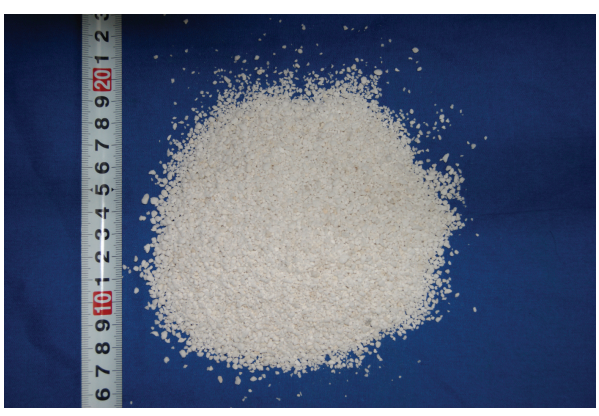

FIGURE 4: The appearance of GHB.

cement paste can combine together in the form of covalent bond. This is the case of lightweight aggregate concrete with GHB. Through chemical reaction, the diffusion layer between the cement paste and aggregate is formed with different composition and structure from those of cement paste or aggregate. The bond strength between the cement paste and light aggregate is high. The hydration products of cement can partly seep into the holes on the surface of the light aggregate with coarse and porous surface structure. Consequently, the two will mesh together closely soon after the cement has hardened. The interfacial bond strength is high for the strong mechanical force acting between the cement paste and light aggregate. Thus, the chemical and mechanical effects contribute significantly to the bond strength between aggregate and cement paste. The main characteristic of the ITZ in normal concrete is that the bulky crystals of AFt and $\mathrm{Ca}(\mathrm{OH})_{2}$ enrich the ITZ and assume the directional arrangement. The $\mathrm{C} / \mathrm{S}$ ratio is high and the structure of ITZ is more flexible than that of paste matrix. Thus, ITZ is the weakest zone in concrete to serve as the invasion channel for many harmful substances. In the lightweight aggregate concrete, the composition and structural characteristics of lightweight aggregate determine the interaction mechanism of light aggregate and cement paste, making it different from that of normal concrete.

Firstly, for lightweight aggregate concrete with GHB, there are many open holes on the coarse surface of GHB. 


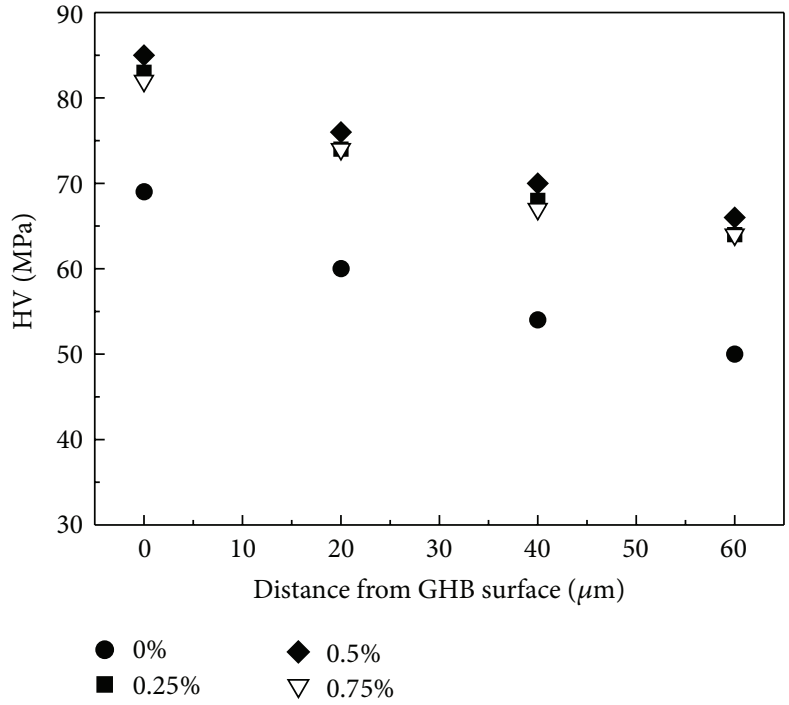

(a)

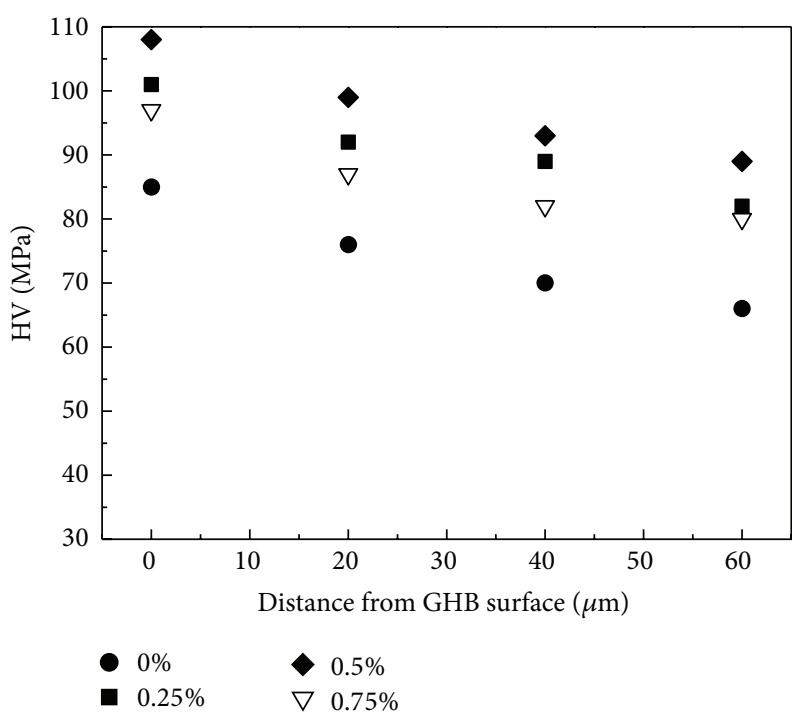

(c)

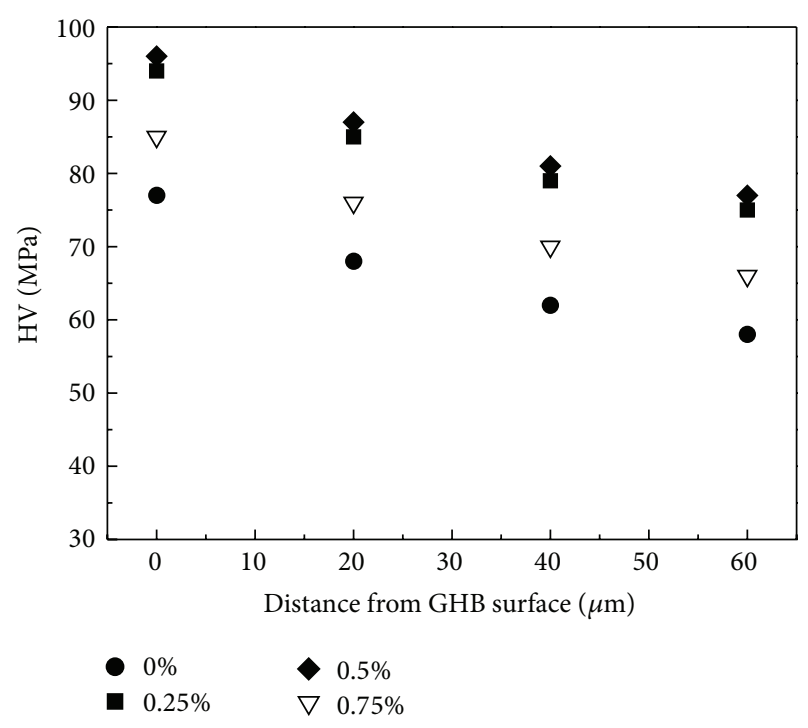

(b)

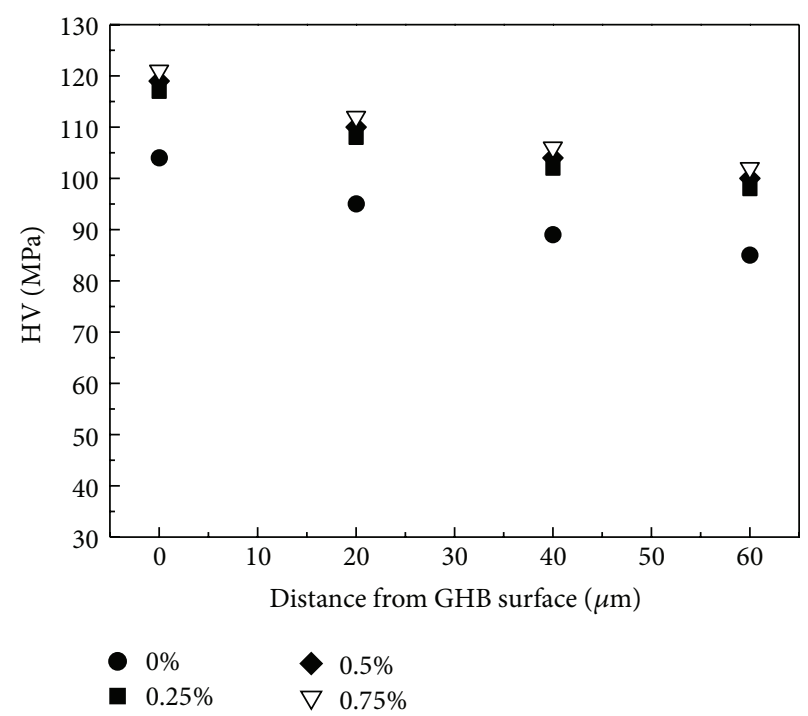

(d)

FIGURE 5: The influence of NS contents on the interfacial HV of lightweight aggregate concrete: (a) $7 \mathrm{~d}$ of water curing, (b) $14 \mathrm{~d}$ of water curing, (c) $28 \mathrm{~d}$ of water curing, and (d) $56 \mathrm{~d}$ of water curing.

There is a strong mechanical action involved in the interaction between GHB and cement paste. Secondly, after calcination at high temperature, the GHB which is mainly composed of silicate and aluminosilicate glass phases; its surface is wrapped with a layer of hard vitreous enclosure and has a certain activity. It reacts with $\mathrm{Ca}(\mathrm{OH})_{2}$, one of the hydration products of cement. Therefore, a certain degree of chemistry exists between GHB and cement paste. Moreover, at the time of mixing concrete, GHB can absorb water from the fresh concrete and store it internally. In the process of cement hydration and hardening, the stored water is gradually released to cure the cement paste around GHB. This is in favor of the cement hydration because it hardens and densifies the interface structure.

\section{Materials and Experimental Method}

2.1. Test Methods for HV [8] Near the Interface Zone. HV test applies a certain load to a hard object (head) with a certain shape and size into a specimen surface, maintain the load for a certain amount of time, and then discharge load. A pyramid impression, whose bottom surface is square, is pressed out in the sample surface. The average length, $d$, is obtained by measuring the two diagonals as shown in Figure 1. The area of impression, $F$, and microhardness (HV) are calculated by Formula (1):

$$
F=\frac{d^{2}}{2 \sin \theta}
$$




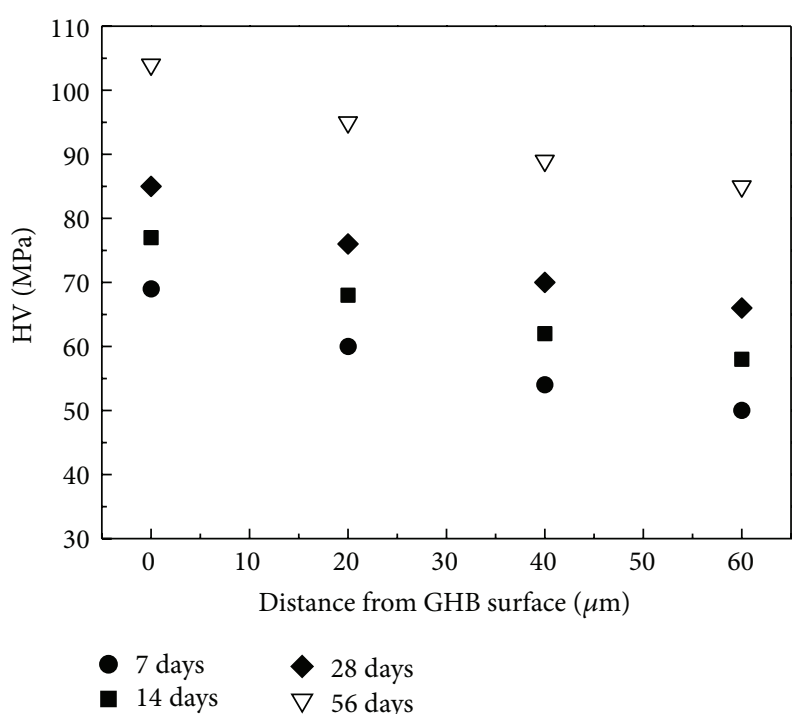

(a)

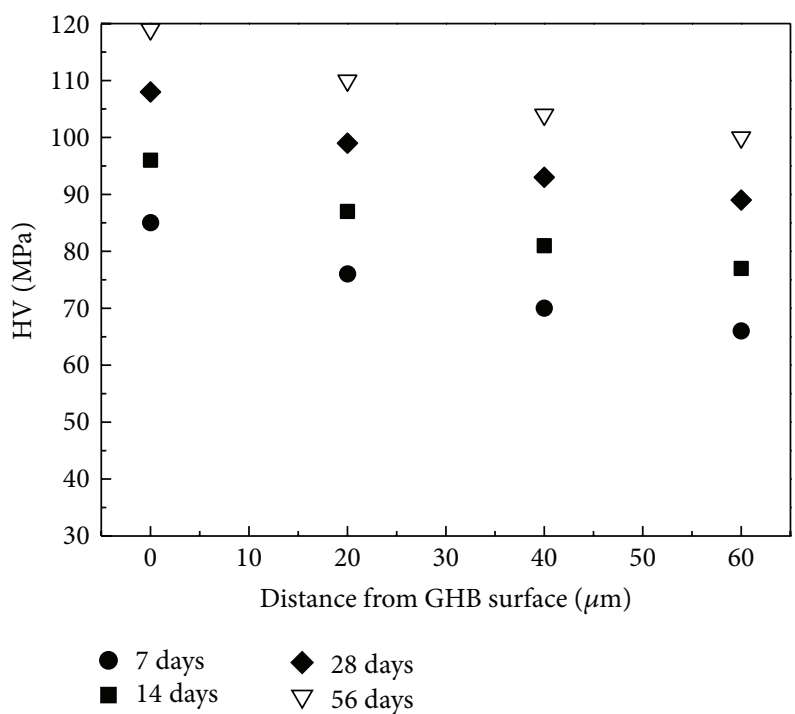

(c)

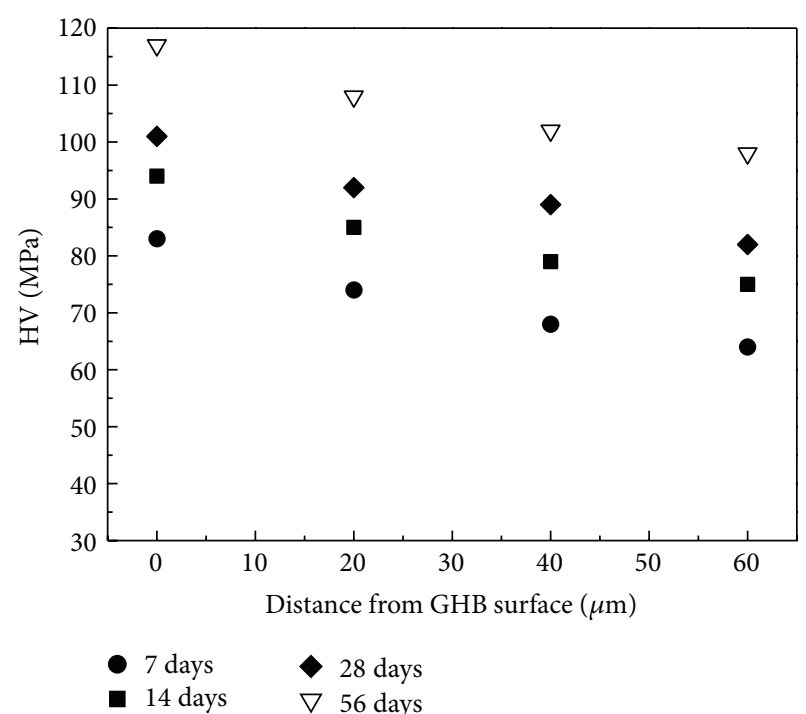

(b)

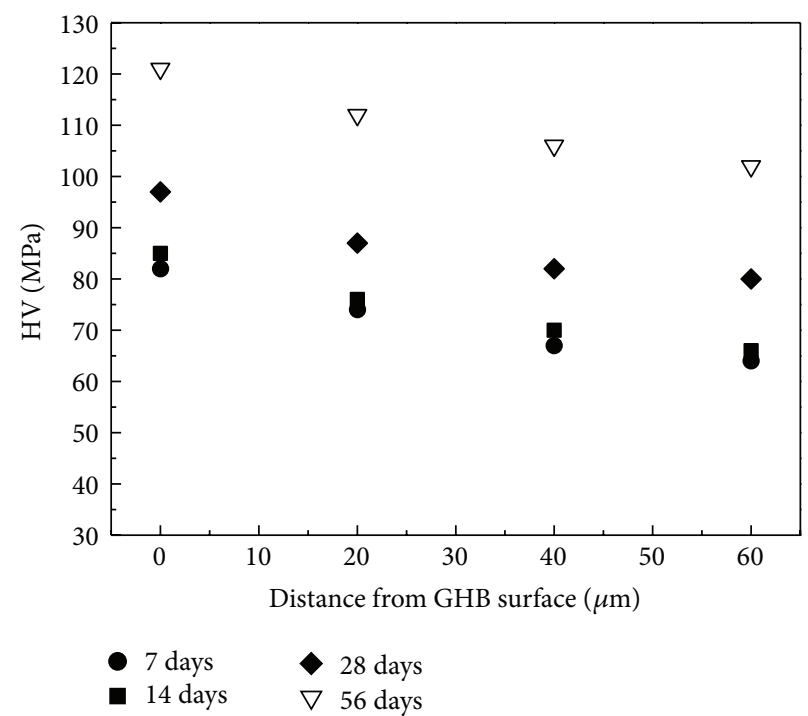

(d)

FIGURE 6: The influence of age of curing on the interfacial HV of lightweight aggregate concrete: (a) NS content $0 \%$, (b) NS content $0.25 \%$, (c) NS content $0.5 \%$, and (d) NS content $0.75 \%$.

TABLE 1: Physical properties of GHB.

\begin{tabular}{lc}
\hline Item & Property \\
\hline Color & White \\
Granularity $/ \mathrm{mm}$ & $0.2 \sim 1.5$ \\
Density $/\left(\mathrm{kg} / \mathrm{m}^{3}\right)$ & $80 \sim 130$ \\
Thermal conductivity $/(\mathrm{W} /(\mathrm{m} \cdot \mathrm{K}))$ & $0.028 \sim 0.045$ \\
Sorptivity $/ \%$ & $20 \sim 40$ \\
\hline
\end{tabular}

where $\theta$ is contact angle between the pressure head and material surface $\left(\theta=68^{\circ}\right)$.
The HV can be calculated by Formula (2):

$$
\mathrm{HV}=\frac{P}{F}
$$

where $P$ is load.

The HV tester of type HXS1000 as shown in Figure 2 was adopted in this study to measure the interface HV. The dot within the scope was $200 \mu \mathrm{m}$ between the GHB surface and cement matrix. The interval was $10 \sim 20 \mu \mathrm{m}$ as shown in Figure 2. The test for each point was repeated ten times, thus providing the result for each point as an average of ten measurements. 
TABLE 2: The chemical composition of cement.

\begin{tabular}{lcccccc}
\hline \multirow{2}{*}{ Test item } & \multirow{2}{*}{ Fineness $/ \%$} & Specific surface & \multicolumn{2}{c}{ Setting time $/ \mathrm{h}$} & \multicolumn{3}{c}{ Compressive strength/MPa } \\
& & area $/\left(\mathrm{m}^{2} / \mathrm{kg}\right)$ & Initial set & Final set & $3 \mathrm{~d}$ & $28 \mathrm{~d}$ \\
\hline Technical indicator & 1.65 & 320 & 3 & 4.5 & 26.4 & 51.0 \\
\hline
\end{tabular}

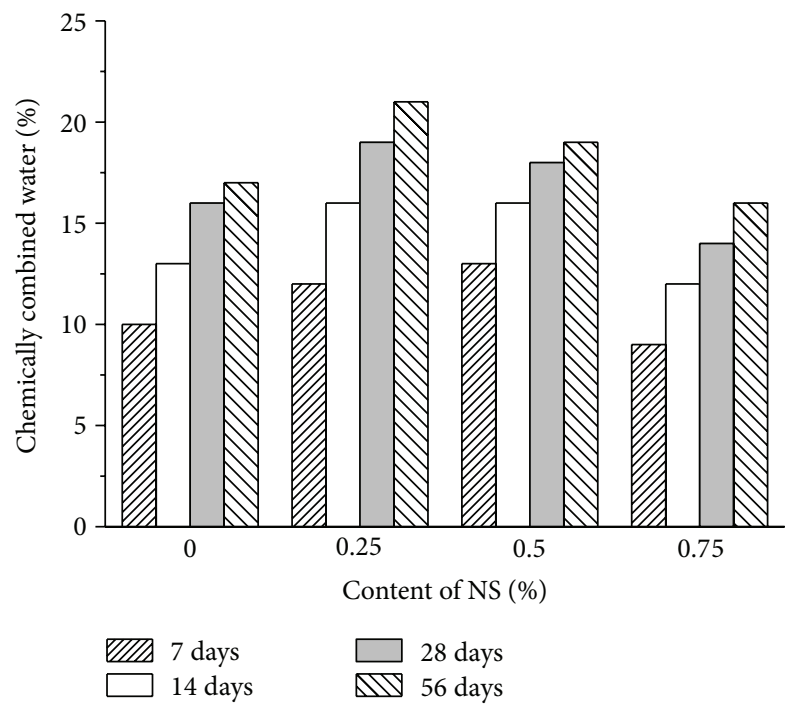

FIGURE 7: The influence of NS content on the CCW of cement paste around GHB.

TABLE 3: Physical properties of NS.

\begin{tabular}{lc}
\hline Name & Nanosilica \\
\hline Appearance & White powder \\
Primary particle size $/ \mathrm{nm}$ & 20 \\
Purity $/ \%$ & $>99.5$ \\
PH & $4-7$ \\
Specific surface $\mathrm{area} /\left(\mathrm{m}^{2} / \mathrm{g}\right)$ & 300 \\
Bulk density $/\left(\mathrm{g} / \mathrm{cm}^{3}\right)$ & 0.10 \\
Surface property & Hydrophilic \\
\hline
\end{tabular}

2.2. Test Method for Chemically Combined Water (CCW) Near the Interface Zone. The testing method of CCW is as follows. The samples cured for a specified age were soaked in absolute alcohol and ground to $80 \mu \mathrm{m}$. The ground powder of the sample was dried to constant weight at $105^{\circ} \mathrm{C}$. About $\mathrm{l} \sim 2 \mathrm{~g}$ sample was weighed for placing into a crucible and burnt up in muffle furnace at $950^{\circ} \mathrm{C}$ for $20 \sim 30 \mathrm{~min}$. Finally, the sample was cooled to room temperature. The test sample for CCW in this research was cement paste obtained after removing the coarse and fine aggregate from mix proportion of concrete, other ingredients remaining unchanged. The sample was used to simulate and measure hydration rate of cement in the concrete. The calculation of CCW volume was based on the sample after calcination. Unit CCW of gel material was calculated according to Formula (3):

$$
W_{\text {nel }}=\frac{W_{1}-W_{2}}{W_{2}}=\frac{R_{f c}}{1-R_{f c}},
$$

$R_{f c}=P_{f} R_{f}+P_{c} R_{c}$

where $W_{\text {nel }}-\mathrm{CCW}$ included in unit mass of gelled material, $\%, W_{1}$ - the mass of sample before calcination, $g ; W_{2}$-the mass of sample after calcination, $g ; P_{f}, P_{c}$-the percent of fly ash and cement in gelled material, respectively; $R_{f}, R_{c}$-the loss on ignition of fly ash and cement, respectively.

\subsection{Materials}

2.3.1. Thermal Insulation Particles. The appearance and physical properties of GHB are shown in Figure 4 and Table 1, respectively.

\subsubsection{Cementing Materials}

(1) Cement. Cement used in this study was ordinary Portland cement with a $28 \mathrm{~d}$ compressive strength of $42.5 \mathrm{MPa}$. The chemical composition of the cement is presented in Table 2.

(2) Nanosilica (NS). The appearance and physical properties of NS are shown in Figure 3 and Table 3, respectively.

2.3.3. Coarse Aggregate and Fine Aggregate. The physical properties of coarse aggregate and fine aggregate are shown in Table 4, respectively.

2.3.4. Water and Superplasticizer. The physical properties of water and water reducing agent are shown in Table 5, respectively.

\subsection{Mixing Design and Preparation of the Sample}

2.4.1. Mixing Design of the Sample. The basic mix design of lightweight aggregate concrete is shown in Table 6. Grouping combinations and mixture ratio for the test are shown in Table 7.

\subsubsection{Manufacturing Method of the Sample}

(1) The size of concrete sample used for measuring HV was $100 \mathrm{~mm} \times 100 \mathrm{~mm} \times 100 \mathrm{~mm}$. The samples were demolded after $24 \mathrm{~h}$ and placed in a standard curing room to cure until required age. The upper and lower ends of the sample of about $20 \mathrm{~mm}$ in length were sliced off to eliminate the influence of segregation on test result. Slices around $15 \mathrm{~mm}$ in thickness were taken from the middle portion and polished for HV testing. 
TABLE 4: Physical properties of the aggregates.

\begin{tabular}{lccccc}
\hline Type & $\begin{array}{c}\text { Apparent } \\
\text { density } /\left(\mathrm{g} / \mathrm{cm}^{3}\right)\end{array}$ & $\begin{array}{c}\text { Water } \\
\text { content/\% }\end{array}$ & $\begin{array}{c}\text { Water } \\
\text { absorption/\% }\end{array}$ & $\begin{array}{c}\text { Sediment } \\
\text { percentage/\% }\end{array}$ & Crush index/\% \\
\hline $\mathrm{G}$ & 2.68 & 0.5 & 2.3 & 0.8 & 9.5 \\
$\mathrm{~S}$ & 2.70 & 1.2 & 3.6 & 1.4 & $\ldots$ \\
\hline
\end{tabular}

TABLE 5: Properties of high-efficiency water reducer.

\begin{tabular}{lccc}
\hline Water reducing rate $/ \%$ & $\mathrm{PH}$ & Density $/\left(\mathrm{g} / \mathrm{cm}^{3}\right)$ & Solid content $/ \%$ \\
\hline $35 \sim 40$ & 7 & 1.08 & 20 \\
\hline
\end{tabular}
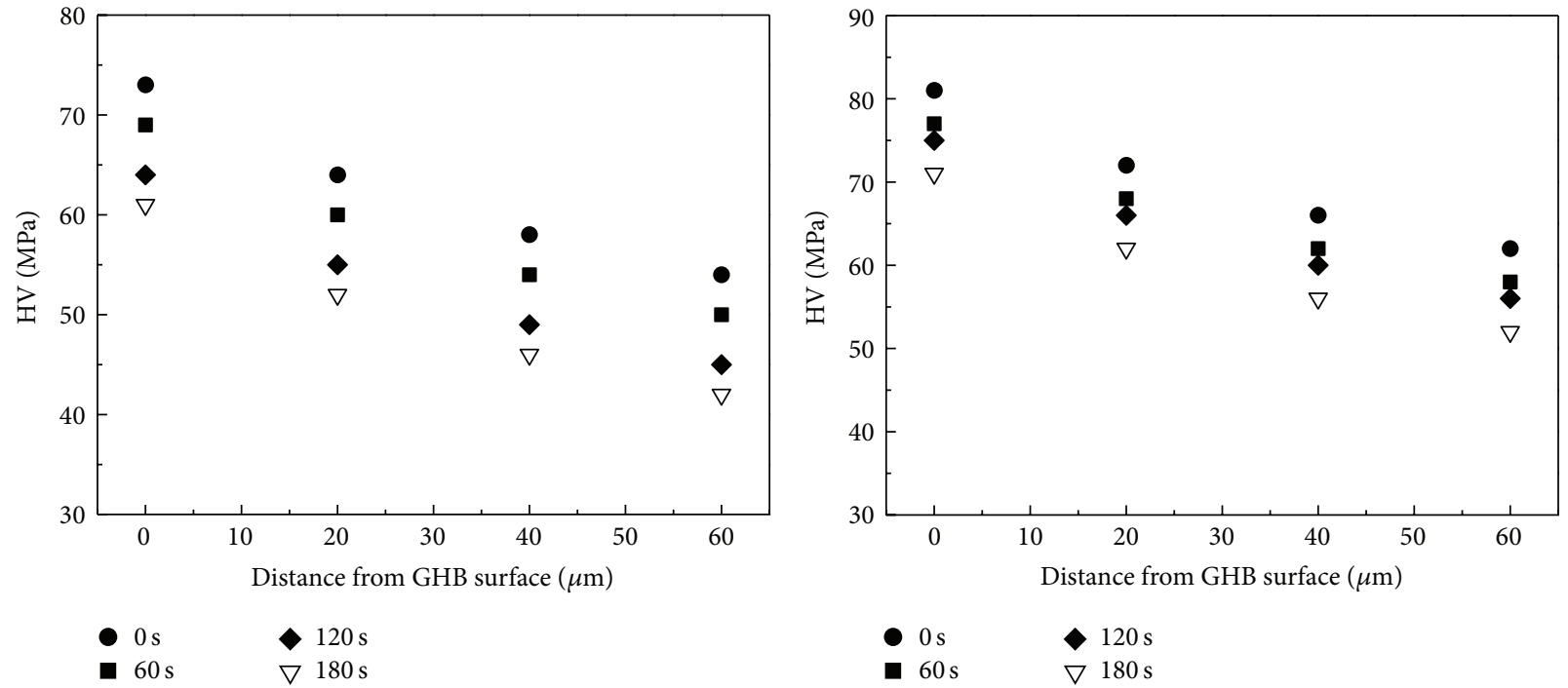

(a)

(b)
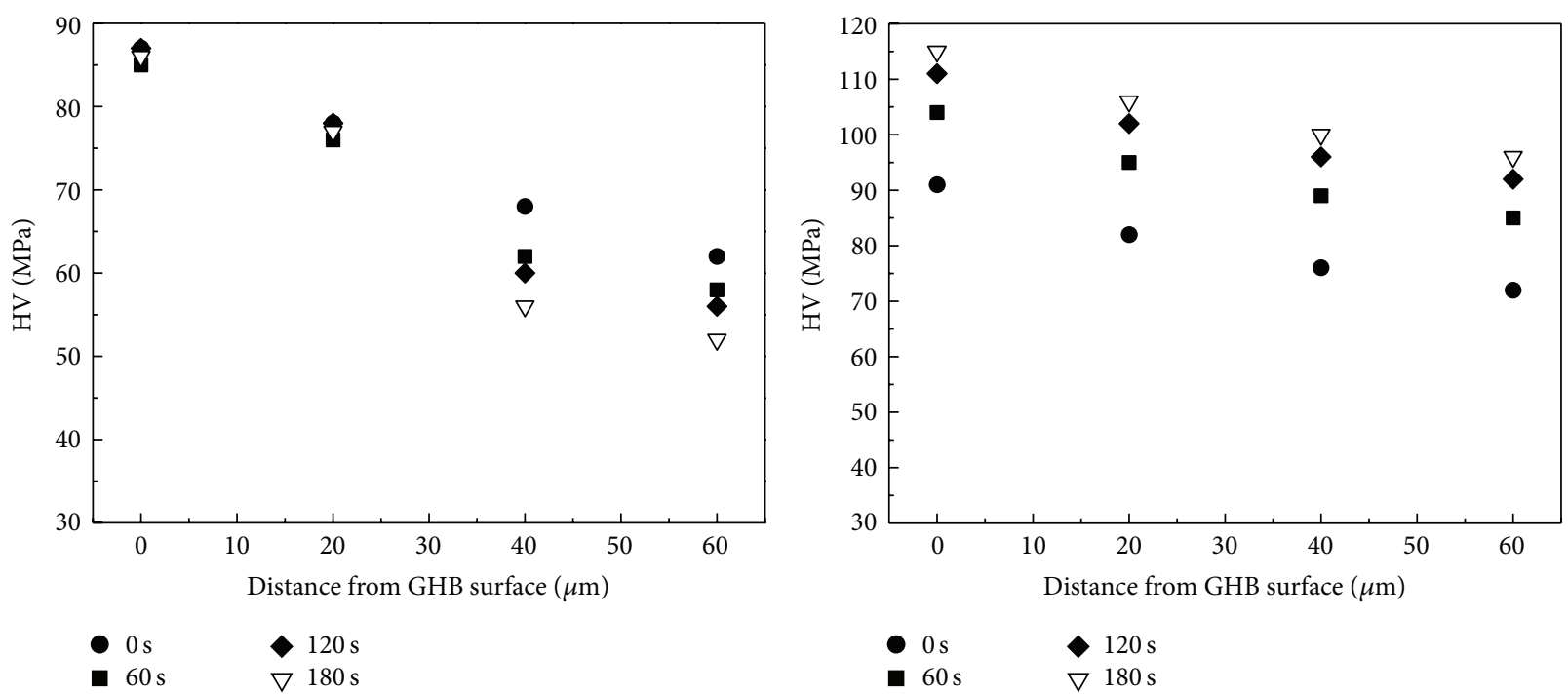

(c)

(d)

FIGURE 8: The influence of prewetting time of GHB on the interfacial HV of lightweight aggregate concrete: (a) $7 \mathrm{~d}$ of water curing, (b) $14 \mathrm{~d}$ of water curing, (c) $28 \mathrm{~d}$ of water curing, and (d) $56 \mathrm{~d}$ of water curing. 
TABLE 6: Mixing design of lightweight aggregate concrete.

\begin{tabular}{lcccc}
\hline Cement/kg & $\begin{array}{c}\text { Coarse } \\
\text { aggregate/kg }\end{array}$ & $\begin{array}{c}\text { Fine } \\
\text { aggregate/kg }\end{array}$ & GHB/kg & $\begin{array}{c}\text { Water reducing } \\
\text { agent } / \mathrm{kg}\end{array}$ \\
\hline 318 & 978 & 419 & 121 & 4.3 \\
\hline
\end{tabular}

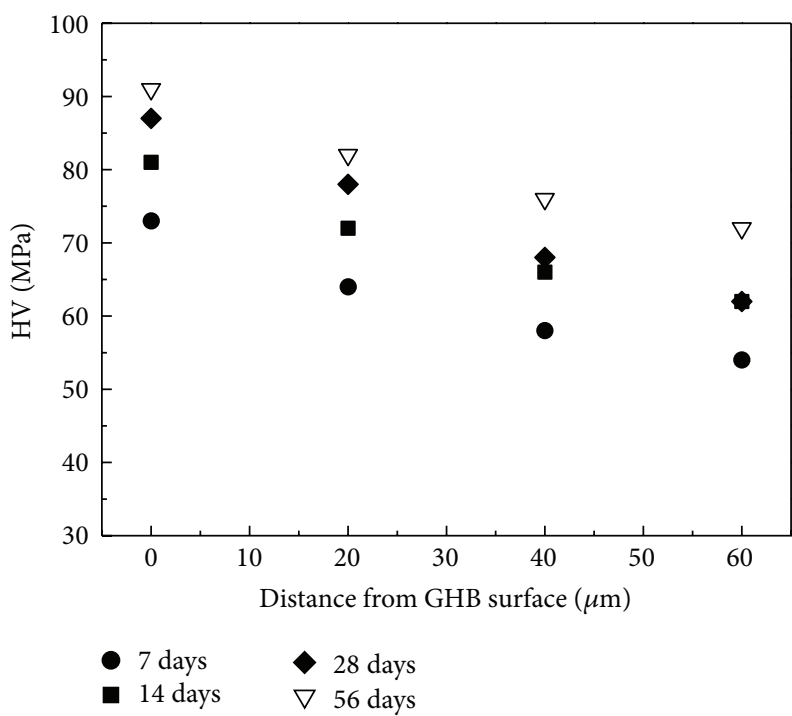

(a)

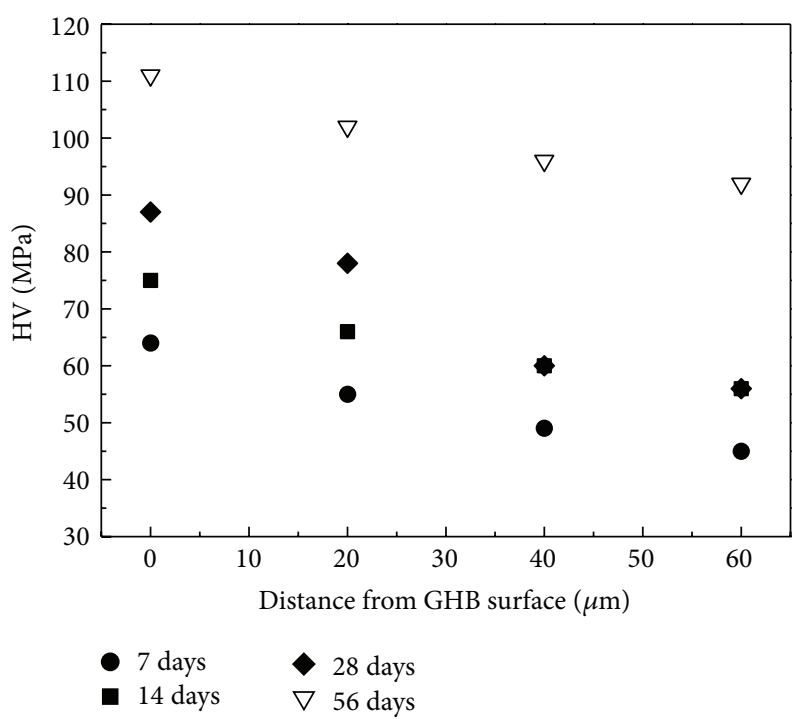

(c)

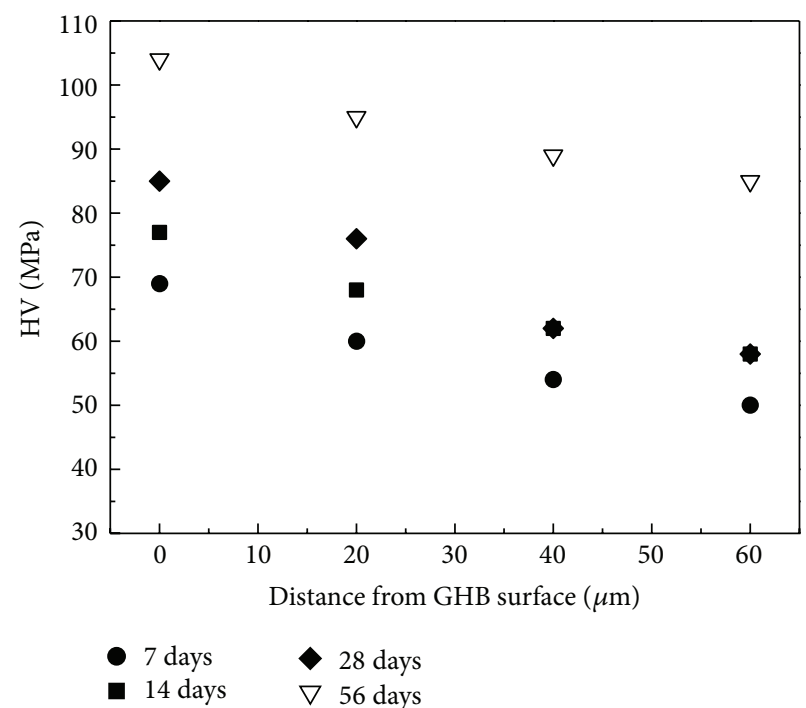

(b)

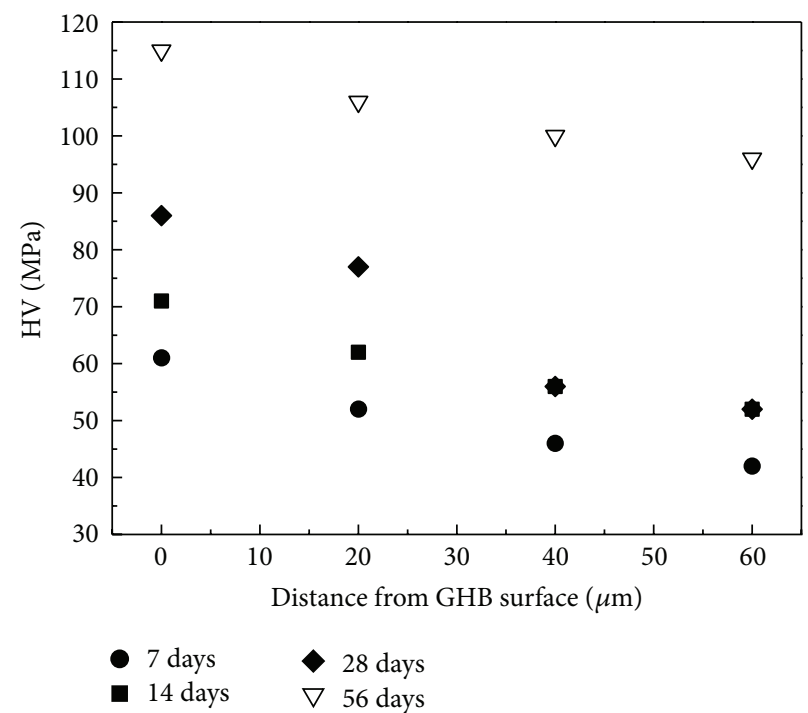

(d)

Figure 9: The influence of prewetting time of GHB on the interfacial $\mathrm{HV}$ of lightweight aggregate concrete: (a) prewetting time $0 \mathrm{~s}$, (b) prewetting time $60 \mathrm{~s}$, (c) prewetting time $90 \mathrm{~s}$, and (d) prewetting time $180 \mathrm{~s}$.

(2) The interface HD can be represented by determining CCW. The cement paste sample was used to test CCW in this test, the coarse and fine aggregates were removed from concrete mixture, and remaining composition was unchanged. Samples were broken when required age was reached. The cement paste was selected from the portion within about
$0.5 \mathrm{~mm}$ away from surface of the GHB. The hydration was terminated with acetone and the samples were dried to constant mass at $60^{\circ} \mathrm{C}$. The dried sample was ground to powder with particle size $<80 \mu \mathrm{m}$. The CCW was determined to test the interface $\mathrm{HD}$ in lightweight aggregate concrete under various conditions. 
TABLE 7: Experimental grouping design and mixing ratios.

\begin{tabular}{|c|c|c|c|c|c|c|}
\hline \multirow{2}{*}{ Group } & \multicolumn{2}{|c|}{ Sample number } & \multirow{2}{*}{ Content of NS } & \multirow{2}{*}{$\begin{array}{l}\text { Prewetting } \\
\text { time/s }\end{array}$} & \multirow{2}{*}{$\begin{array}{l}\text { Water cement } \\
\quad \text { ratio }\end{array}$} & \multirow{2}{*}{ Curing humidity } \\
\hline & $\begin{array}{l}\text { Sample number for } \\
\text { HV }\end{array}$ & $\begin{array}{l}\text { Sample number for } \\
\text { CCW content }\end{array}$ & & & & \\
\hline \multirow{4}{*}{ NS (nanosilica) } & NS1 & $\mathrm{ns} 1$ & $0 \%$ & 60 & 0.55 & $90 \%$ \\
\hline & NS2 & $\mathrm{ns} 2$ & $0.25 \%$ & 60 & 0.55 & $90 \%$ \\
\hline & NS3 & ns3 & $0.5 \%$ & 60 & 0.55 & $90 \%$ \\
\hline & NS4 & $\mathrm{ns} 4$ & $0.75 \%$ & 60 & 0.55 & $90 \%$ \\
\hline \multirow{4}{*}{$\mathrm{P}$ (prewetting) } & $\mathrm{P} 1$ & $\mathrm{p} 1$ & $0 \%$ & 0 & 0.55 & $90 \%$ \\
\hline & $\mathrm{P} 2$ & $\mathrm{p} 2$ & $0 \%$ & 60 & 0.55 & $90 \%$ \\
\hline & $\mathrm{P} 3$ & p3 & $0 \%$ & 120 & 0.55 & $90 \%$ \\
\hline & $\mathrm{P} 4$ & $\mathrm{p} 4$ & $0 \%$ & 180 & 0.55 & $90 \%$ \\
\hline \multirow{3}{*}{$\mathrm{W}(\mathrm{W} / \mathrm{B})$} & W1 & w1 & $0 \%$ & 60 & 0.45 & $90 \%$ \\
\hline & W2 & w2 & $0 \%$ & 60 & 0.5 & $90 \%$ \\
\hline & W3 & w3 & $0 \%$ & 60 & 0.55 & $90 \%$ \\
\hline \multirow{3}{*}{ RH (relative humidity) } & RH1 & rhl & $0 \%$ & 60 & 0.55 & $30 \%$ \\
\hline & RH2 & rh2 & $0 \%$ & 60 & 0.55 & $60 \%$ \\
\hline & RH3 & rh3 & $0 \%$ & 60 & 0.55 & $90 \%$ \\
\hline
\end{tabular}

\section{Influencing Factors on the Interface $\mathrm{HV}$ of Lightweight Aggregate Concrete}

3.1. The Influence of Different NS Contents on the Interface HV and HD. Test results on different NS contents on the interface $\mathrm{HV}$ are shown in Figure 5. It can be seen from Figure 5 that, with the increase of NS content, interface $\mathrm{HV}$ improved. When the age is $7 \mathrm{~d}$ and NS content is $0 \%$, the interface $\mathrm{HV}$ at a location $20 \mu \mathrm{m}$ away from GHB surface (NS1-7 d$20 \mu \mathrm{m})$ is $60 \mathrm{MPa}$. The thickness of interface enhancement layer (IEL) is $50 \mu \mathrm{m}$. When NS content is $0.25 \%$, the interface $\mathrm{HV}$ at a location $20 \mu \mathrm{m}$ away from GHB surface (NS2-7 d$20 \mu \mathrm{m})$ is $74 \mathrm{MPa}$, and the thickness of IEL is $60 \mu \mathrm{m}$. When NS content is $0.5 \%$, the interface $\mathrm{HV}$ of $20 \mu \mathrm{m}$ away from GHB surface (NS3-7 d-20 $\mu \mathrm{m}$ ) is $76 \mathrm{MPa}$, and the thickness of IEL is $60 \mu \mathrm{m}$. When NS content is $0.75 \%$, the interface HV of $20 \mu \mathrm{m}$ away from GHB surface (NS4-7 d-20 $\mu \mathrm{m}$ ) is $72 \mathrm{MPa}$, and the thickness of IEL is $50 \mu \mathrm{m}$.

The change in interface $\mathrm{HV}$ of lightweight aggregate concrete with curing age for same NS content is shown in Figure 6. It can be seen that with increase in curing age, both the interface $\mathrm{HV}$ and the range of the interface increased. When NS content is $0 \%$, the interface $\mathrm{HV}$ increased at a faster rate until $28 \mathrm{~d}$ water curing but increased slowly after $28 \mathrm{~d}$ water curing.

When NS content is $1 \%$, the interface HV of NS1-7 d$40 \mu \mathrm{m}$ is $68 \mathrm{MPa}$, NS1-28 d- $40 \mu \mathrm{m}$ is $89 \mathrm{MPa}$, and NS1-56 d$40 \mu \mathrm{m}$ is $102 \mathrm{MPa}$. The interface HV increased by $31 \%$ when the curing age increased from $7 \mathrm{~d}$ to $28 \mathrm{~d}$. The interface $\mathrm{HV}$ increased by $15 \%$ when the curing age increased from $28 \mathrm{~d}$ to $56 \mathrm{~d}$.

When NS content is $4 \%$, HV of NS4-7 d- $40 \mu \mathrm{m}$ is $67 \mathrm{MPa}$, NS4-28 d-40 $\mu \mathrm{m}$ is $82 \mathrm{MPa}$, and NS4-56 d-40 $\mu \mathrm{m}$ is $106 \mathrm{MPa}$. The interface $\mathrm{HV}$ increased $22 \%$ when the curing age increased from $7 \mathrm{~d}$ to $28 \mathrm{~d}$. The interface $\mathrm{HV}$ increased $29 \%$

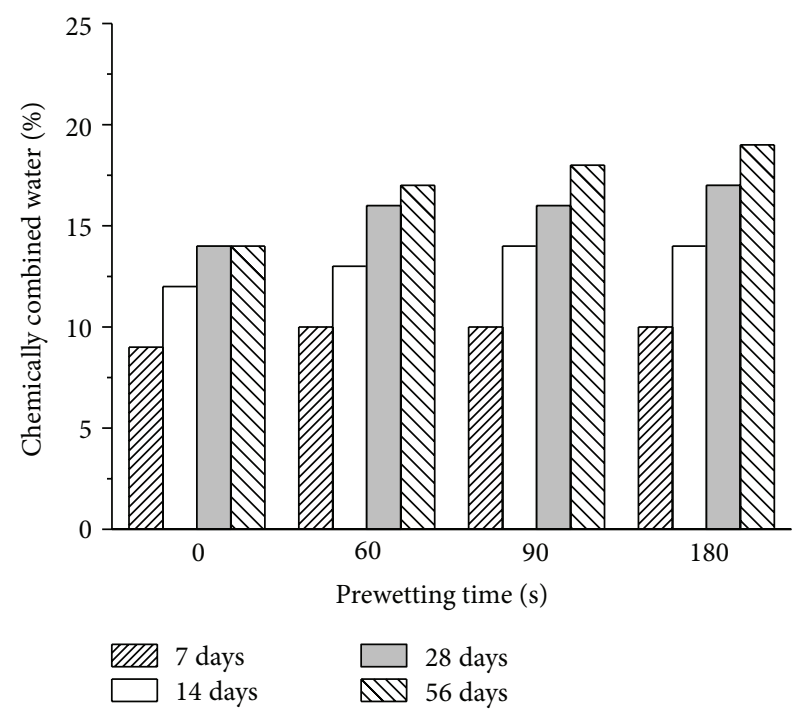

FIGURE 10: The influence of prewetting time on the CCW of cement paste around GHB.

when the curing age increased from $28 \mathrm{~d}$ to $56 \mathrm{~d}$. The interface $\mathrm{HV}$ increase would slow down before cement hydration.

It can be seen from Figure 7 that the CCW of cement pastes around GHB increased with increasing NS content. At $28 \mathrm{~d}$ age, when NS content is $0 \%$, the CCW of cement paste near GHB (the ns1-28 d) is $16 \%$. When NS content is $0.25 \%$, the CCW of cement paste near GHB (the ns2-28d) is $19 \%$; when NS content is $0.5 \%$, the CCW of cement paste near GHB (the ns3-28 d) is $18 \%$; when NS content is $0.75 \%$, the CCW of cement paste near GHB (the ns4-28 d) is $14 \%$.

The NS and GHB were mixed during the prewetting processing. For GHB with higher water absorption, its surface 

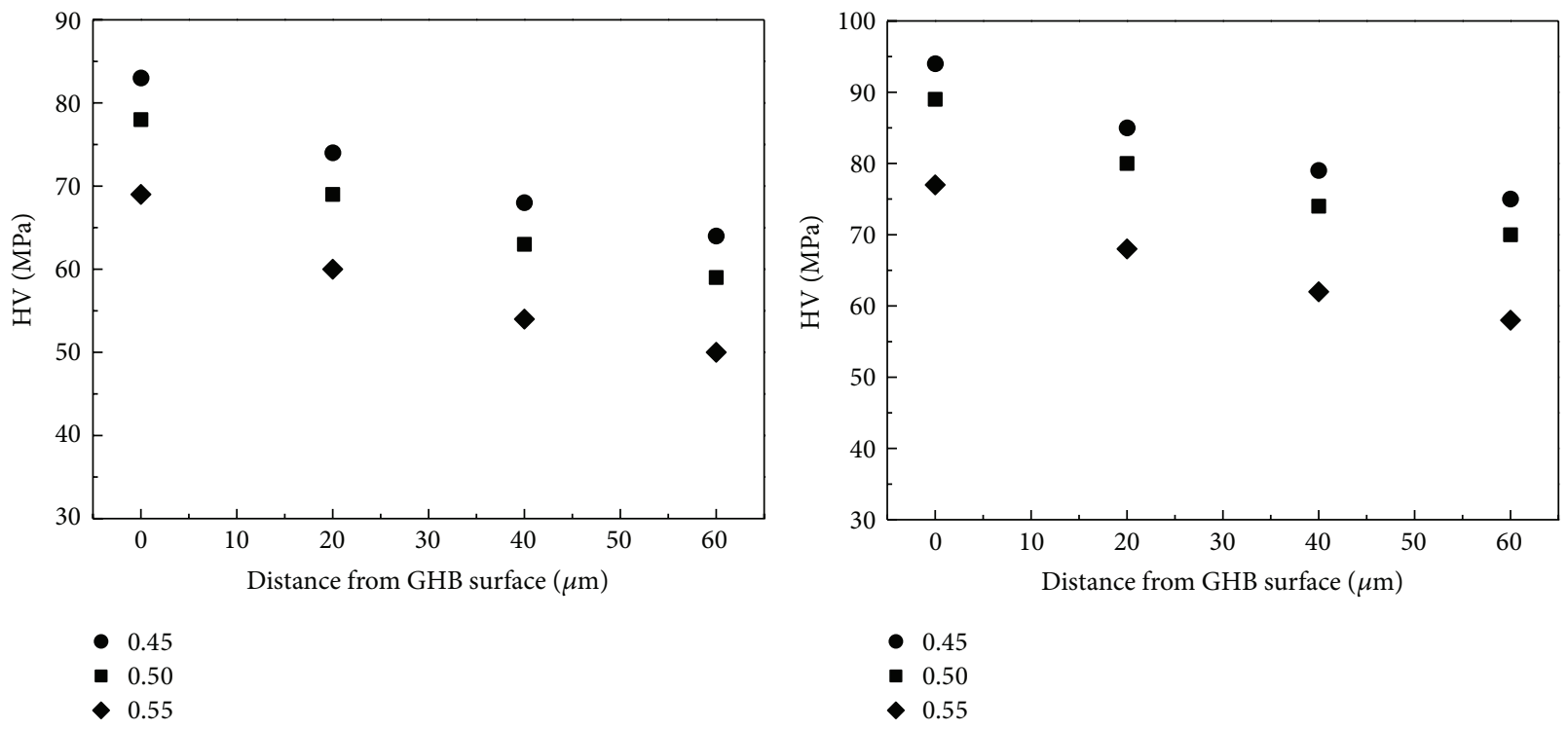

- 0.45

- 0.50

- 0.55

(a)

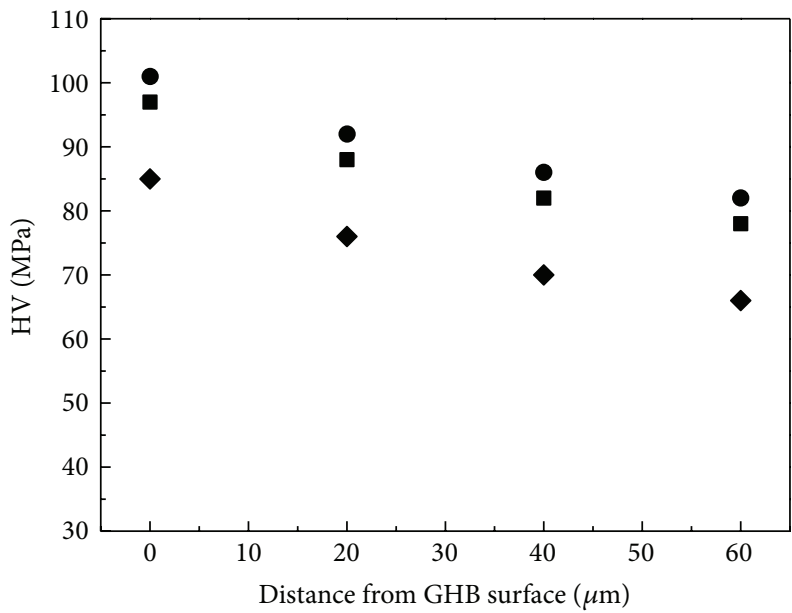

- 0.45

- 0.50

- 0.55

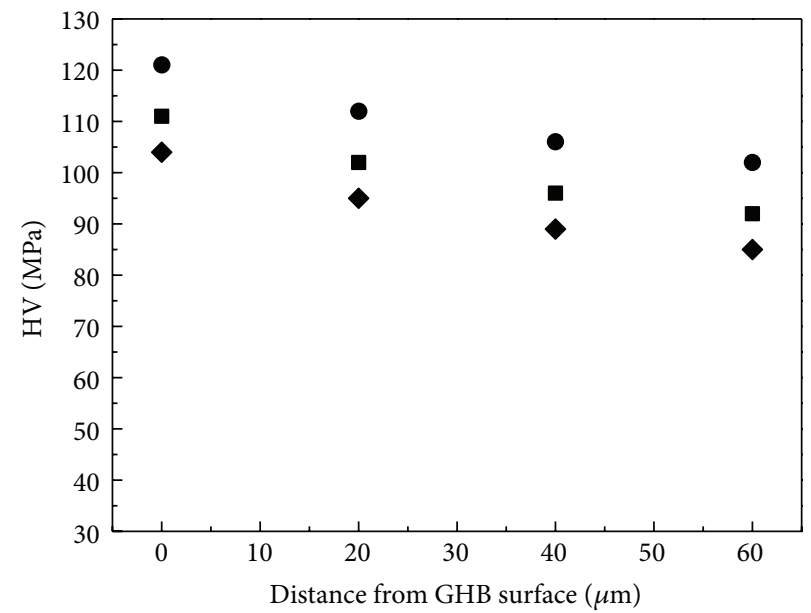

- 0.45

- 0.50

$\bullet 0.55$

(c)

(d)

FIGURE 11: The influence of water to cement ratio on the interfacial HV of cement paste ((a) for $7 \mathrm{~d}$, (b) for $14 \mathrm{~d}$, (c) for $28 \mathrm{~d}$, and (d) for $56 \mathrm{~d}$ ).

forms a layer of water film of few microns in the mixing process, and the NS with super large specific surface area could adsorb plenty of free water; thus, there are a large number of NS with very small size particles adhering to the surface of GHB by hydraulic effect. In the process of mixing, although it is easy to form weak areas with a large amount of calcium hydroxide near the interface of lightweight aggregate in cement hydration, the NS adhering to the interface area of GHB has higher activity and can quickly generate secondary reactions with $\mathrm{Ca}(\mathrm{OH})_{2}$ products to form $\mathrm{C}-\mathrm{S}-\mathrm{H}$ gel with higher strength. The interfacial microstructure of the concrete gained more importance. The large-sized $\mathrm{Ca}(\mathrm{OH})_{2}$ crystals on the interface of GHB are few and some NS, which is not involved in reaction, filled in the pores between $\mathrm{C}$ $\mathrm{S}-\mathrm{H}$. After mixing with NS, a higher amount of a higher amount of $\mathrm{C}-\mathrm{H}$ formed linkage linkages and with $\mathrm{C}-\mathrm{S}-\mathrm{H}$ on the NS surface to reduce the content of $\mathrm{Ca}(\mathrm{OH})_{2}$ formed linkages with $\mathrm{C}-\mathrm{S}-\mathrm{H}$ on the NS surface to reduce the content of $\mathrm{Ca}(\mathrm{OH})_{2}$ and refine the $\mathrm{Ca}(\mathrm{OH})_{2}$ crystals. With NS as the core, $\mathrm{C}-\mathrm{S}-\mathrm{H}$ formed a clustering structure and NS behaved as mesh node for the C-S-H. At the same time, NS filled the micropores of GHB interface and absorbed the $\mathrm{Ca}(\mathrm{OH})_{2}$ formed by hydration efficiently; as a result the microhardness on the interface zone of the GHB increased rapidly during early period of hydration, and the $\mathrm{CCW}$ of cement pastes around the GHB also increased.

When the internal relative humidity of the concrete reduces to a critical value, the hydration reaction will stop. When the NS content is $0.75 \%$, due to its high specific surface zone, after mixing with cement, the amount of surface water 


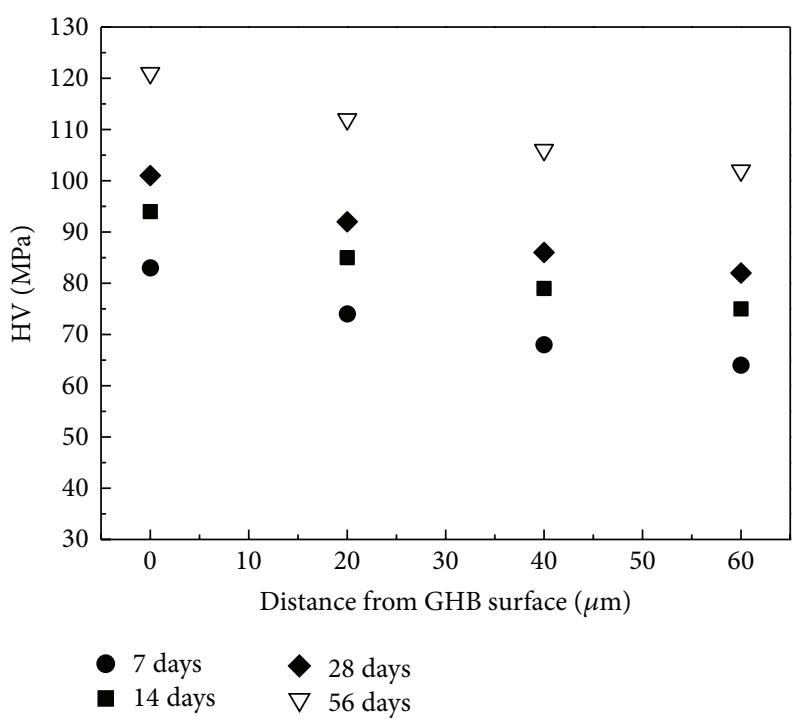

(a)

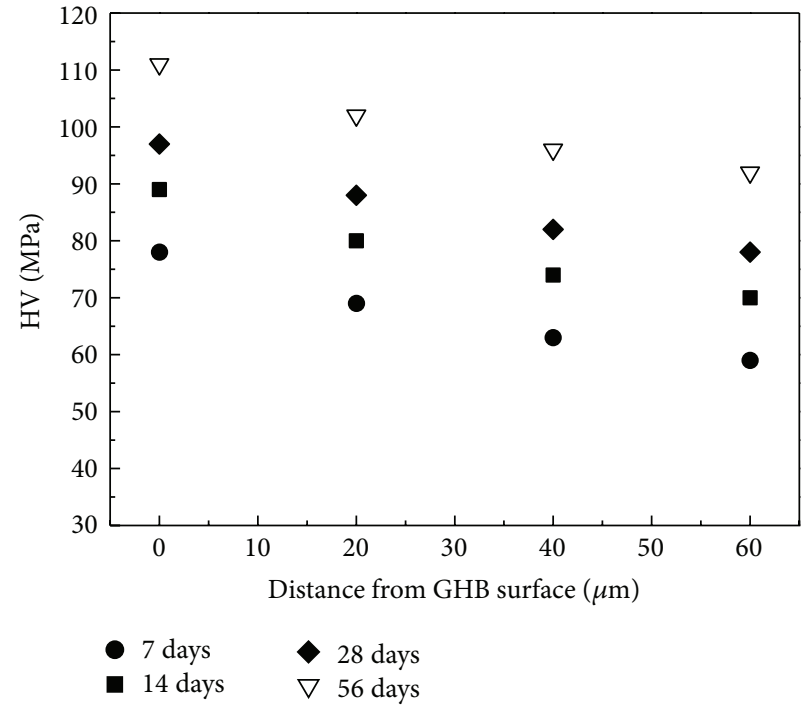

(b)

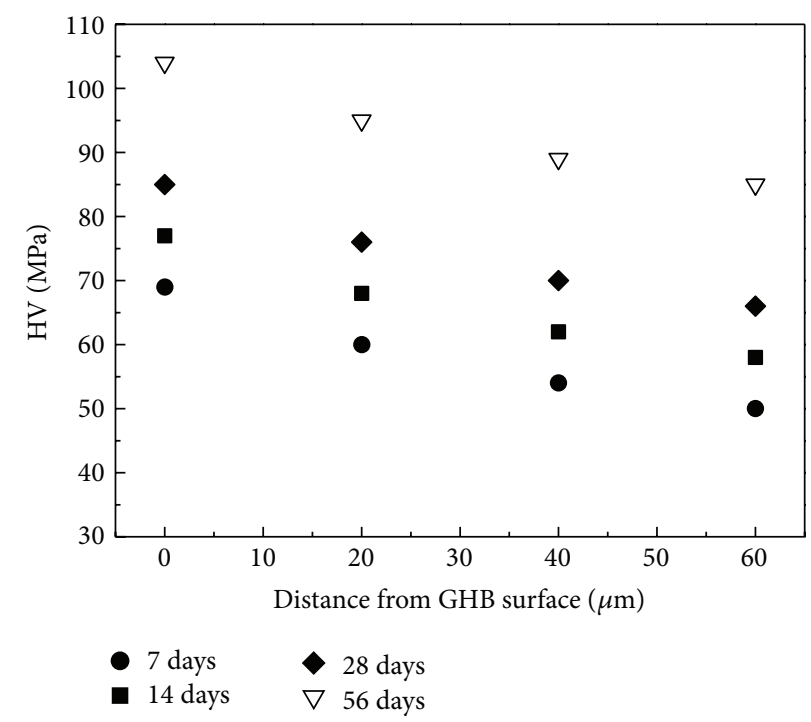

(c)

FIGURE 12: The influence of age of curing on the interfacial HV of cement paste at different water to cement ratios ((a) for 0.45 , (b) for 0.5 , and (c) for 0.55$)$.

adsorbed by NS is very large leading to a reduction in amount of water participating in the hydration process. In particular, in low water to cement ratio of concrete, this phenomenon is damaging and it can reduce degree of cement hydration and slow down the early growth of interface microhardness, causing the interface HD to reduce. So during early period of hydration, the interfacial HV grows slowly, and the CCW at the interface zone is somewhat reduced.

3.2. The Influence of Different Prewetting Times of GHB on the Interface $H V$ and $H D$ of Lightweight Aggregate Concrete. The influence of different prewetting times of GHB on the interface $\mathrm{HV}$ of lightweight aggregate concrete is shown in Figure 8 . It can be seen with the increase of prewetting time of GHB, the interface $\mathrm{HV}$ increased during the early stage of hydration process and the interface $\mathrm{HV}$ reduced in the later stage of hydration process. The interfacial HV of P1-7 d-20 $\mu \mathrm{m}$ is $64 \mathrm{MPa}$ when the thickness of IEL is $40 \mu \mathrm{m}$. The interfacial $\mathrm{HV}$ of $\mathrm{P} 2-7 \mathrm{~d}-20 \mu \mathrm{m}$ is $60 \mathrm{MPa}$ when the thickness of IEL is $50 \mu \mathrm{m}$. The interfacial $\mathrm{HV}$ of $\mathrm{P} 3-7 \mathrm{~d}-20 \mu \mathrm{m}$ is $55 \mathrm{MPa}$ when the thickness of IEL is $65 \mu \mathrm{m}$. The interfacial HV of P4-7 d$20 \mu \mathrm{m}$ is $52 \mathrm{MPa}$ when the thickness of IEL is $70 \mu \mathrm{m}$.

The variation in the interfacial HV of lightweight aggregate concrete with curing age for same prewetting time is shown in Figure 9. It can be seen that as the curing age increases, both the interfacial $\mathrm{HV}$ and the range of the interface increased. For prewetting time of $0 \mathrm{~s}$, the interface $\mathrm{HV}$ increased at a faster rate until $28 \mathrm{~d}$ of water curing but increased slowly after $28 \mathrm{~d}$. The interfacial HV of P1-7 d$40 \mu \mathrm{m}$ is $58 \mathrm{MPa}$, for P1-28 d- $40 \mu \mathrm{m}$ it is $68 \mathrm{MPa}$, and for P1$56 \mathrm{~d}-40 \mu \mathrm{m}$ the interfacial $\mathrm{HV}$ is $76 \mathrm{MPa}$. The interfacial $\mathrm{HV}$ increased by $17 \%$ when the curing age increased to $28 \mathrm{~d}$ from 
$7 \mathrm{~d}$. The interfacial HV increased $12 \%$ when the curing age increased to $56 \mathrm{~d}$ from $28 \mathrm{~d}$.

Interfacial $\mathrm{HV}$ of $\mathrm{P} 2-7 \mathrm{~d}-40 \mu \mathrm{m}$ is $54 \mathrm{MPa}$ after $7 \mathrm{~d}$ water curing, for P2-28d-40 $\mu \mathrm{m}$ it is $62 \mathrm{MPa}$, and for P2-56d$40 \mu \mathrm{m}$ interfacial $\mathrm{HV}$ is $89 \mathrm{MPa}$. The interfacial $\mathrm{HV}$ increased by $15 \%$ when the curing age increased from $7 \mathrm{~d}$ to $28 \mathrm{~d}$. The interfacial $\mathrm{HV}$ increased $44 \%$ when the curing age increased from $28 \mathrm{~d}$ to $56 \mathrm{~d}$. The interfacial $\mathrm{HV}$ increased rapidly during the late stage of hydration process after prewetting.

It can be seen from Figure 10 that with the increase of GHB prewetting time, CCW of cement paste near GHB increased gradually. The CCW of p1-56 d is $14 \%$, for p2-56 dit is $17 \%$, for $\mathrm{p} 3-56 \mathrm{~d}$ it is $18 \%$, and for $\mathrm{p} 4-56 \mathrm{~d}$ the CCW is $19 \%$.

The strong water absorption effect inside the lightweight aggregate concrete with GHB without prewetting makes the interface zone structure narrower. Thus, the interfacial HV of the lightweight aggregate concrete without prewetting is higher than that of others before $28 \mathrm{~d}$. However, interfacial $\mathrm{HV}$ increased slowly afterwards. The interfacial HV for $56 \mathrm{~d}$ increased by $5 \%$ compared to that for prewetting period of $28 \mathrm{~d}$. For lightweight aggregate concrete with prewetting, at $7 \mathrm{~d}$ of age, the interfacial $\mathrm{HV}$ of P4-7 d is lower than that of P2-7 d. The higher the prewetting degree of GHB, the weaker the internal water absorption effect in the early age of $7 \mathrm{~d}$, and the smaller the reduction of water to cement ratio near the interface. However, since then, the strength increased rapidly and reached to $86 \mathrm{MPa}$ and $115 \mathrm{MPa}$ in $28 \mathrm{~d}$ and $56 \mathrm{~d}$, respectively.

3.3. Influence of Water-Cement Ratio on HV and HD in the Interface Zone. The influence of water to cement ratio on the interface HV is shown in Figure 11. It can be seen that with the increase in water to cement ratio, the interfacial HV in both the matrix and the interface zone is reduced and the range of interface zone increased. The HV of W1-7 d-20 $\mu \mathrm{m}$ is $74 \mathrm{MPa}$ when the thickness of IEL is about $60 \mu \mathrm{m}$; HV of W2-7 d-20 $\mu \mathrm{m}$ is $69 \mathrm{MPa}$ when the thickness of IEL is $70 \mu \mathrm{m}$, and $\mathrm{HV}$ of W3-7 d-20 $\mu \mathrm{m}$ is $60 \mathrm{MPa}$, when the thickness of IEL is $85 \mu \mathrm{m}$. For the same water to cement ratio, the changes in interfacial HV with age are shown in Figure 12. For each ratio of water to cement, the $\mathrm{HV}$ in the interface and the matrix increased with age and the range of interface zone also increased. When the water-cement ratio is relatively small, the interfacial HV increased at a faster rate at the early age and at a slower rate at the later ages (after $28 \mathrm{~d}$ ). As shown in Figure 12, the HV of W1-7 d- $40 \mu \mathrm{m}$ is $68 \mathrm{MPa}$ when the thickness of IEL is $50 \mu \mathrm{m}$; HV of W1-28 d- $40 \mu \mathrm{m}$ is $86 \mathrm{MPa}$ when the thickness of IEL is $60 \mu \mathrm{m}$; HV of W1-56 d-40 $\mu \mathrm{m}$ is $106 \mathrm{MPa}$ when the thickness of IEL was $80 \mu \mathrm{m}$. The increase in $\mathrm{HV}$ from $7 \mathrm{~d}$ to $28 \mathrm{~d}$ is $26.5 \%$. The increase of $\mathrm{HV}$ from $28 \mathrm{~d}$ to $56 \mathrm{~d}$ is $23.0 \%$.

It can be seen from Figure 13, with the increase in water to cement ratio, the CCW of cement paste near GHB increased gradually. At $28 \mathrm{~d}$ age, the CCW of $\mathrm{wl}-28 \mathrm{~d}$ is $15 \%$ and the CCW of w3-28d is $16 \%$. When the water to cement ratio is small, due to the low content of free water inside the normal concrete for cement hydration,so the unhydrated

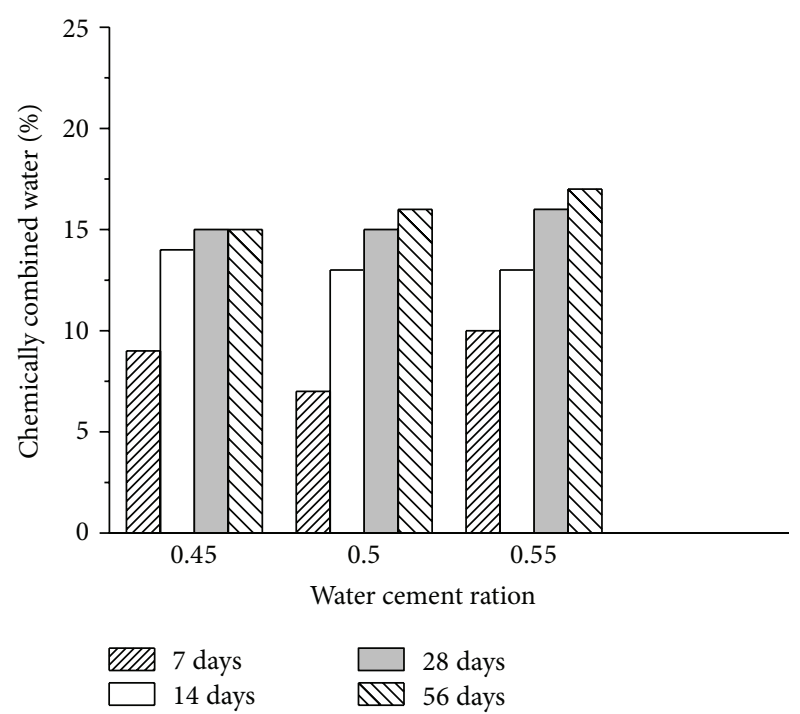

FIgURE 13: The influence of water to cement ratio on the CCW of cement paste close to GHB.

cement particles are abundant and the strength of cement paste is lower in the early age. However, inside the lightweight aggregate concrete with low water to cement ratio, GHB released water at the early age to meet the water demand for cement hydration, and the increase in interfacial HV is noticeable during the early stage of curing. When the water to cement ratio is high, hydration of cement dominated in the early age of curing, and GHB has little effect on the hydration of cement paste in its vicinity. After being withheld for a long time, the water in GHB is gradually released to replenish water needed by cement paste close to it. Therefore, water desorption effect of GHB is concentrated in the late stage of curing. However, the cement hydration speed is slowed in the later curing age to result in showing little contribution of the internal curing effect of GHB.

On the other hand, the water absorption of GHB is far greater than the other aggregates such as gravel and sand. The GHB could absorb water slowly at the early stage of concrete mixing and curing, especially the unsaturated GHB in prewetting processing. A large amount of free water migrated to the core of GHB through capillary action and enriched the interfacial area between GHB and cement. An appreciable amount of interfacial water enriched regions is formed. When the water-cement ratio of lightweight aggregate concrete is higher, the water enrichment near GHB is especially obvious in the early stage. In the later period of cement hydration and surface evaporation, more micropores are formed in the interface water enrichment region after losing water, and the structure of GHB interface zone becomes loose. The lightweight aggregate concrete with lower cement water ratio is found to contain little free water. The free water concentrating near the GHB is relatively small during the early period of hydration, so the interfacial zone of the light aggregate is relatively dense and strong. 

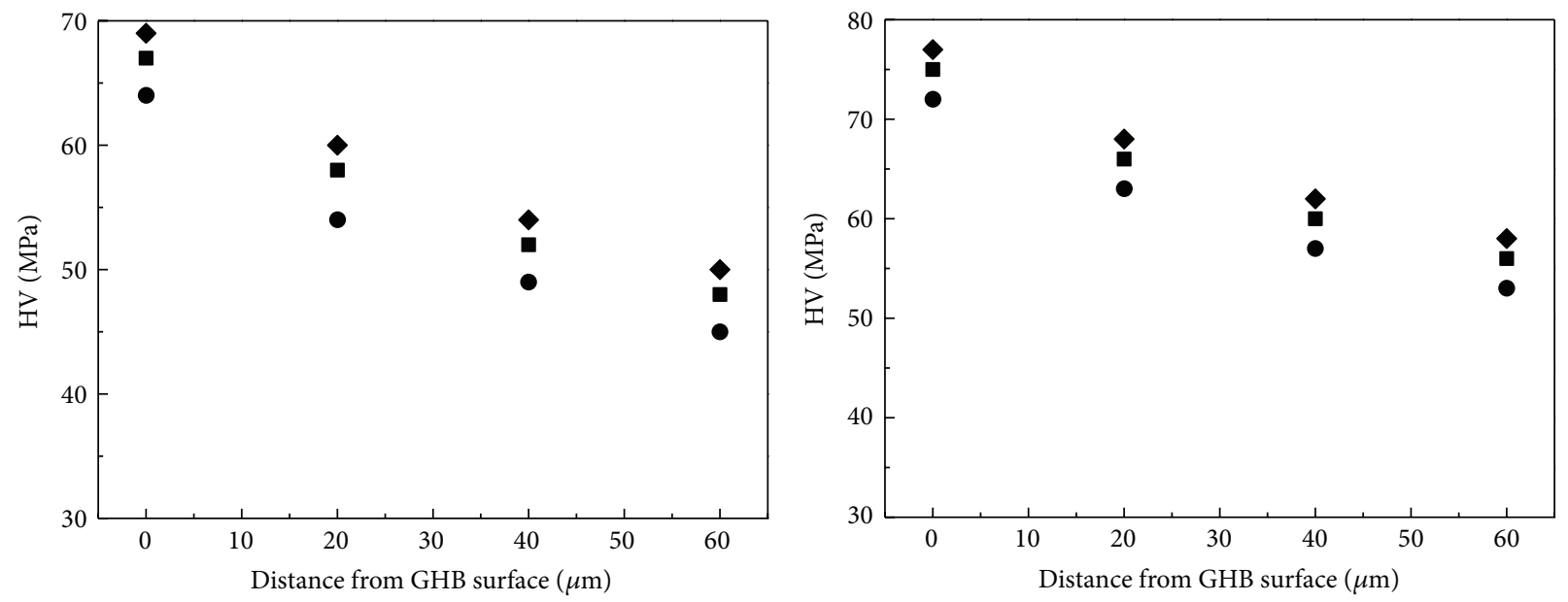

$$
\begin{array}{r}
30 \\
\text { - } 60 \\
-\quad 90
\end{array}
$$

(a)

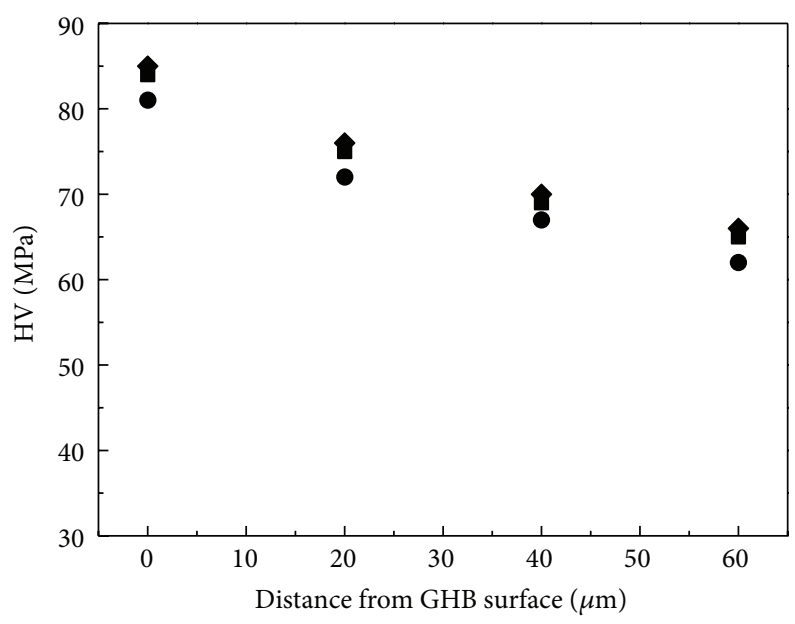

$$
\text { - } 30
$$$$
\text { - } 60
$$$$
\text { - } 90
$$
- 30
- 60
- 90

(b)

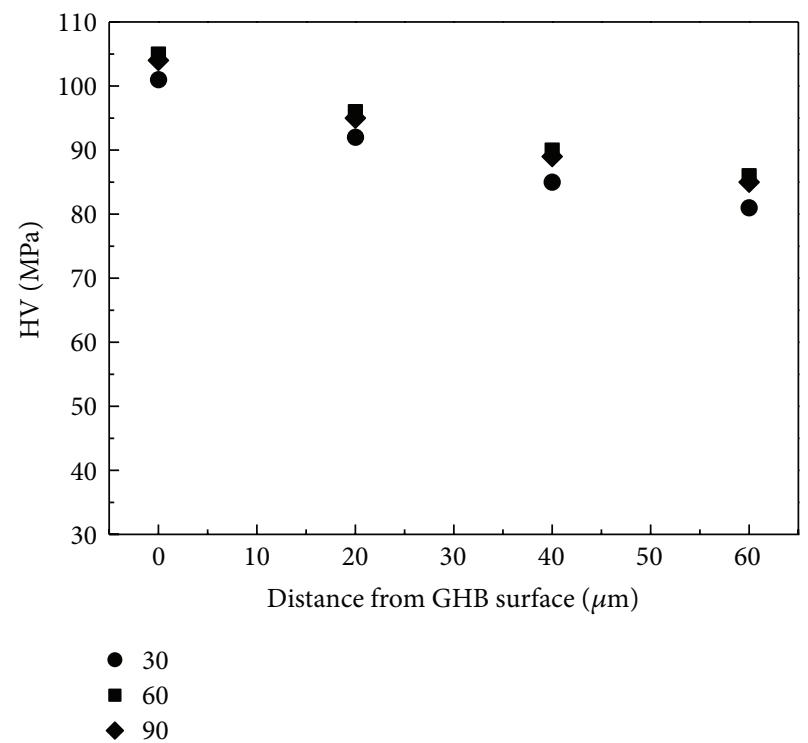

(d)

FIGURE 14: The influence of age of curing on the interfacial $\mathrm{HV}$ of cement paste at different levels of relative humidity ((a) for $7 \mathrm{~d}$, (b) for $14 \mathrm{~d}$, (c) for $28 \mathrm{~d}$, and (d) for $56 \mathrm{~d}$ ).

3.4. Influence of Relative Humidity on $H V$ and HD in Interface Zone. Three levels of RH $(30 \%, 60 \%$, and $90 \%)$ were selected in curing for this test. RH 90\% was obtained in the standard curing room. Other two relative humidity conditions were obtained by using appropriate saturated salt solution. The interfacial $\mathrm{HV}$ and $\mathrm{HD}$ were measured to determine the influence of curing process on the interfacial structure.

It can be seen from Figure 14 that in all ages of curing, with the increase of curing humidity, $\mathrm{HV}$ in both the matrix and the interfacial zone increased. The influence of relative humidity on the interfacial $\mathrm{HV}$ is insignificant. As shown in Figure 14, the HV of RH1-7 d-20 $\mu \mathrm{m}, \mathrm{RH} 2-7 \mathrm{~d}-20 \mu \mathrm{m}$, and RH3-7 d-20 $\mu \mathrm{m}$ is $54 \mathrm{MPa}, 58 \mathrm{MPa}$, and $60 \mathrm{MPa}$, respectively.
The HV of RH1-56 d-20 $\mu \mathrm{m}, \mathrm{RH} 2-56 \mathrm{~d}-20 \mu \mathrm{m}$, and RH3-56 d$20 \mu \mathrm{m}$ is $92 \mathrm{MPa}, 96 \mathrm{MPa}$, and $95 \mathrm{MPa}$, respectively.

With the increase in curing relative humidity, the HV in the paste matrix increased. This is because the matrix strength is affected significantly by the curing conditions of the environment. The GHB has little effect on it. However, the interfacial $\mathrm{HV}$ is not only affected by the curing relative humidity but also by the action of the water absorption and desorption effect. The environmental relative humidity has great influence on the internal humidity. The lower the environmental humidity, the greater the water gradient at the surface of $\mathrm{GHB}$, which makes easier the release of water. For the same curing humidity, the influence of curing age on the 


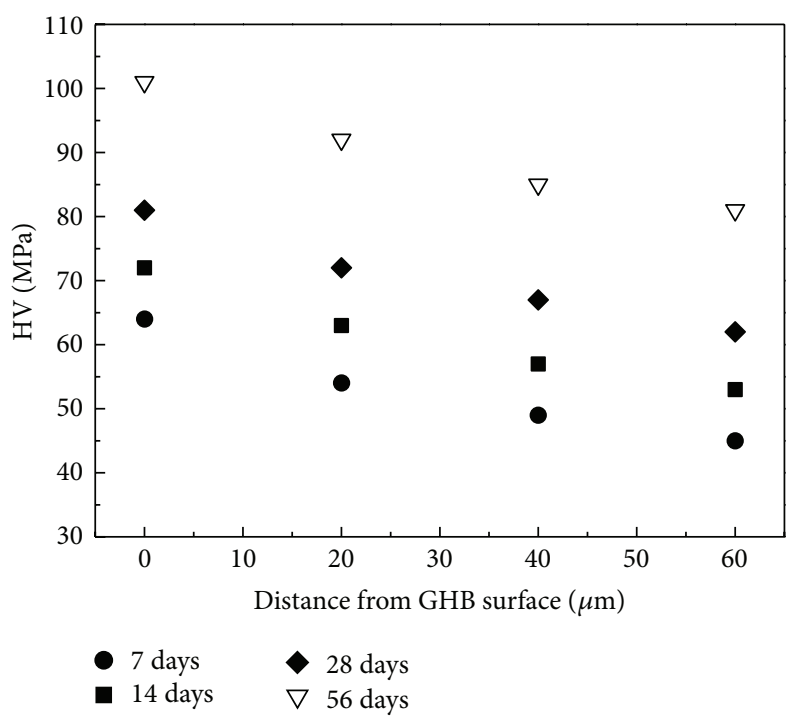

(a)

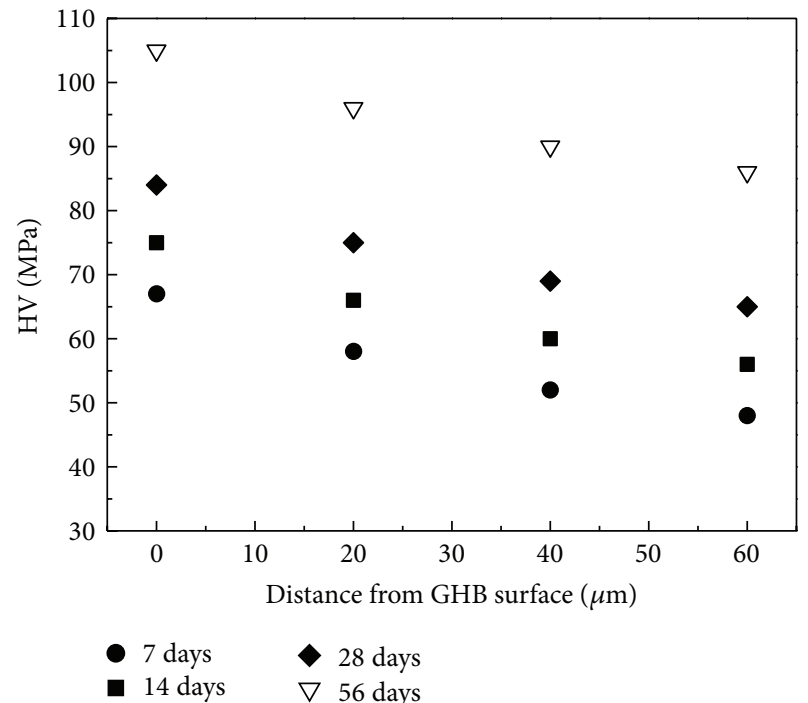

(b)

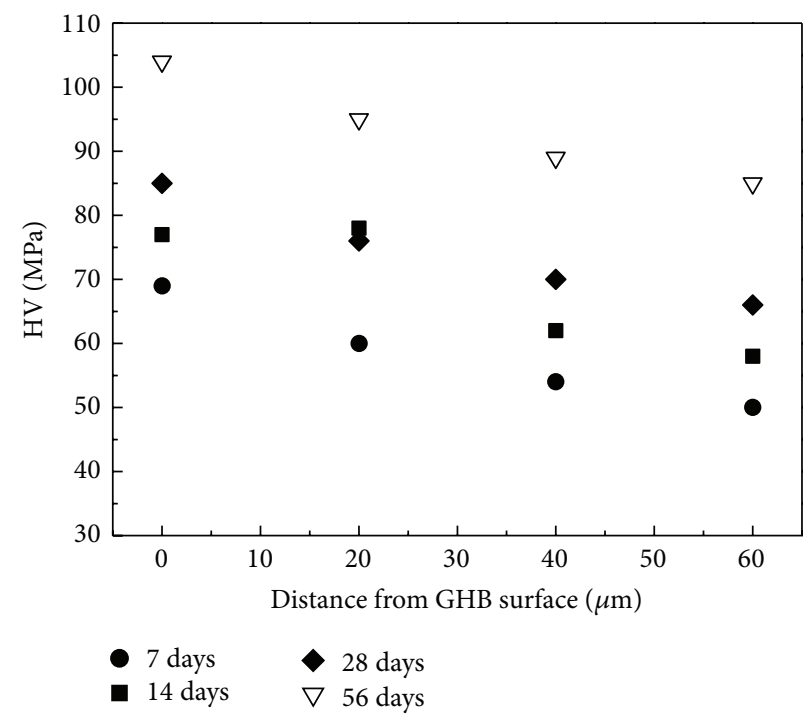

(c)

FIGURE 15: The influence of relative humidity on the interfacial HV of cement paste ((a) for 30\%, (b) for 60\%, and (c) for $90 \%)$.

interfacial HV is shown in Figure 15. It can be seen from the figure that for the same curing condition the interfacial HV and cement matrix gradually increased with age of curing. The thickness of interface enhanced layer also increased slightly.

It can be seen from Figure 15 that, at each age of curing, with increasing curing humidity, the CCW near the GHB increased gradually. Under different levels of $\mathrm{RH}$, at early age of curing, the CCW near GHB changed markedly. At late age of curing, the difference in CCW near GHB is not significant at the $\mathrm{RH}$ of $60 \%$ and $90 \%$. At this stage, the cement paste is very compact and the external curing effect is not noticeable. As shown in Figure 15, the CCW of rh1-7 d, rh2-7 d, and rh3$7 \mathrm{~d}$ is $8 \%, 9 \%$, and $10 \%$, respectively. The CCW of rhl- $56 \mathrm{~d}$, rh2-56 d, and rh3-56 d is $18 \%, 18 \%$, and $17 \%$, respectively. The higher the environmental relative humidity, the better the structure of interfacial zone. However, after $56 \mathrm{~d}$, due to the increase in compactness of the cement paste, the influence of environmental relative humidity is insignificant on the interfacial HD. It can be seen from Figure 16 that, at each level of curing humidity, the CCW near GHB increased with curing age. After $56 \mathrm{~d}$ age of curing with high interfacial HD, the CCW increased slowly.

Thus, it can be concluded that the curing humidity of concrete must be ensured in early curing period. The environmental relative humidity has a significant influence in determining whether the hydration of cement could be carried out normally. When the relative humidity is moderate, the cement hydration proceeds smoothly and the concrete strength fully develops. If the relative humidity is not high enough, the concrete loses water and becomes dry to affect the cement hydration and even stop the hydration, which 


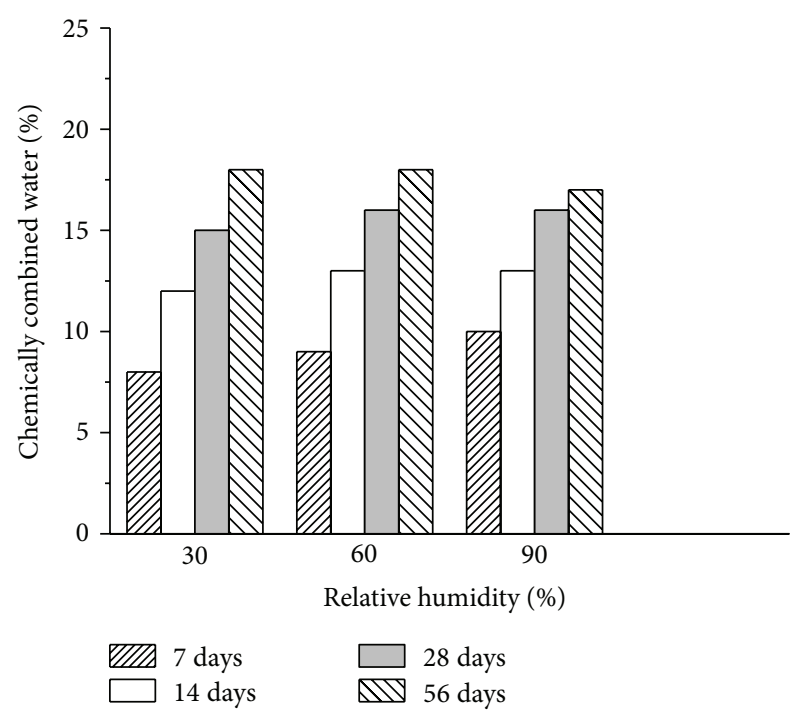

FIGURE 16: The influence of relative humidity on the CCW of cement paste close to GHB.

reduces the strength of concrete. As the hydration reaction of cement progresses, the volume of cement gel in concrete is increased, and the cavity volume of capillary is reduced. In the process of cement hydration, a large amount of free water of concrete is adsorbed gradually by the hydrated gels and the internal water for the cement hydration reaction is gradually reduced. This phenomenon severely reduces the strength of concrete. The internal moisture of GHB is transported through the pores by capillary action in early stage of curing; thus, there is not enough water supply at the interfacial zone between cement gelled material with high performance and the GHB, thus causing the interfacial zone structure of GHB to be relatively loose in the late stage of curing. Therefore, to enhance the external humidity is beneficial to the internal curing effect of lightweight aggregate concrete and to forming a relatively close interfacial zone around the GHB. The internal curing effect of GHB has no influence in the late stage of curing at all levels of relative humidity. This is because as the strength of concrete increases gradually with curing age, the structure of cement paste becomes denser, and the depth to which the external curing water can flow becomes lower. Due to the constant hydration of cement in concrete, the drying process of interior portions of concrete is promoted. At this stage, the water desorption effect of GHB causes the internal relative humidity of GHB to reach higher value than that of concrete, thus enabling the continuous hydration of cement in the later age, and also resulting in the sustained increase in strength.

\section{Conclusions}

(1) Two major approaches to improve the microstructure of the interfacial transition zone of the lightweight aggregate concrete are to mix it with fine mineral admixture and to use the prewetting technique. In this research, the interfacial hydration degree and microhardness have been effectively improved by mixing with nanosized silica and fully mobilizing the internal curing ability of the glazed hollow bead. The targeted improvement in the microstructure of the interfacial transition zone has been achieved.

(2) The HV of cement paste in the ITZ and the matrix increased with age of curing. The thickness of ITZ also increased. The thickness of the interfacial zone between GHB and cement paste varied from $20 \mu \mathrm{m}$ to $70 \mu \mathrm{m}$.

(3) The interface between GHB and cement paste could be optimized by mixing NS, and through internal curing effect of GHB. The $\mathrm{Ca}^{2+}$ ions available from cement hydration participated in the pozzolanic reaction at the surface of GHB to generate the C-S-H complex with low calcium consent. This resulted in effective offsetting of the original defects of GHB, thus increasing the particle strength.

(4) On completion of the process of prewetting, the GHB released its own water for cement hydration at the interface. Under the action of internal curing, the degree of hydration of cement in the interfacial zone was more than that in matrix; the interfacial HV was even greater than that of cement matrix.

(5) With increasing water to cement ratio and the interfacial HD, the interfacial HV and cement matrix declined and the range of interfacial zone increased. With increasing environmental relative humidity, the interfacial $\mathrm{HV}$ and $\mathrm{HD}$ also increased.

\section{Conflict of Interests}

The authors declare that there is no conflict of interests regarding the publication of this paper.

\section{References}

[1] M. H. Zhang and O. E. Gjørv, "Microstructure of the interfacial zone between lightweight aggregate and cement paste," Cement and Concrete Research, vol. 20, no. 4, pp. 613-614, 1990.

[2] M.-H. Zhang and O. E. Gjørv, "Penetration of cement paste into lightweight aggregate," Cement and Concrete Research, vol. 22, no. 1, pp. 47-55, 1992.

[3] H. Shu-guang, Y. Wen, and L. Lin-nu, "Experimental research on influence factors of absorbing and releasing water process of lightweight aggregate," Highway, vol. 10, pp. 155-159, 2006.

[4] D. P. Bentz and K. A. Snyder, "Protected paste volume in concrete: extension to internal curing using saturated lightweight fine aggregate," Cement and Concrete Research, vol. 29, no. 11, pp. 1863-1867, 1999.

[5] C. Hua, P. Acker, and A. Ehrlacher, "Analyses and models of the autogenous shrinkage of hardening cement paste. I. Modelling at macroscopic scale," Cement and Concrete Research, vol. 25, no. 7, pp. 1457-1468, 1995.

[6] Q. Jing-yu, X. Shu-min, G. Yan- ping, and B. Heng-jing, "Microstructure of mixed type aggregate lightweight concrete (I)," Journal of Tongji University, vol. 29, no. 8, pp. 946-953, 2001. 
[7] J.-Y. Qi, Y.-P. Gao, J.-Z. Mang, and H.-J. Ba, "Microstructure of mixed type aggregate lightweight concrete (II)," Journal of Tongji University, vol. 29, no. 10, pp. 1185-1189, 2001.

[8] W.-B. Xu, Z.-H. Shui, J.-T. Ma, and W. Chen, "Carbonation of fly ash concrete investigated with microhardness analysis," Bulletin of the Chinese Ceramic Society, vol. 30, no. 1, pp. 7-12, 2011. 

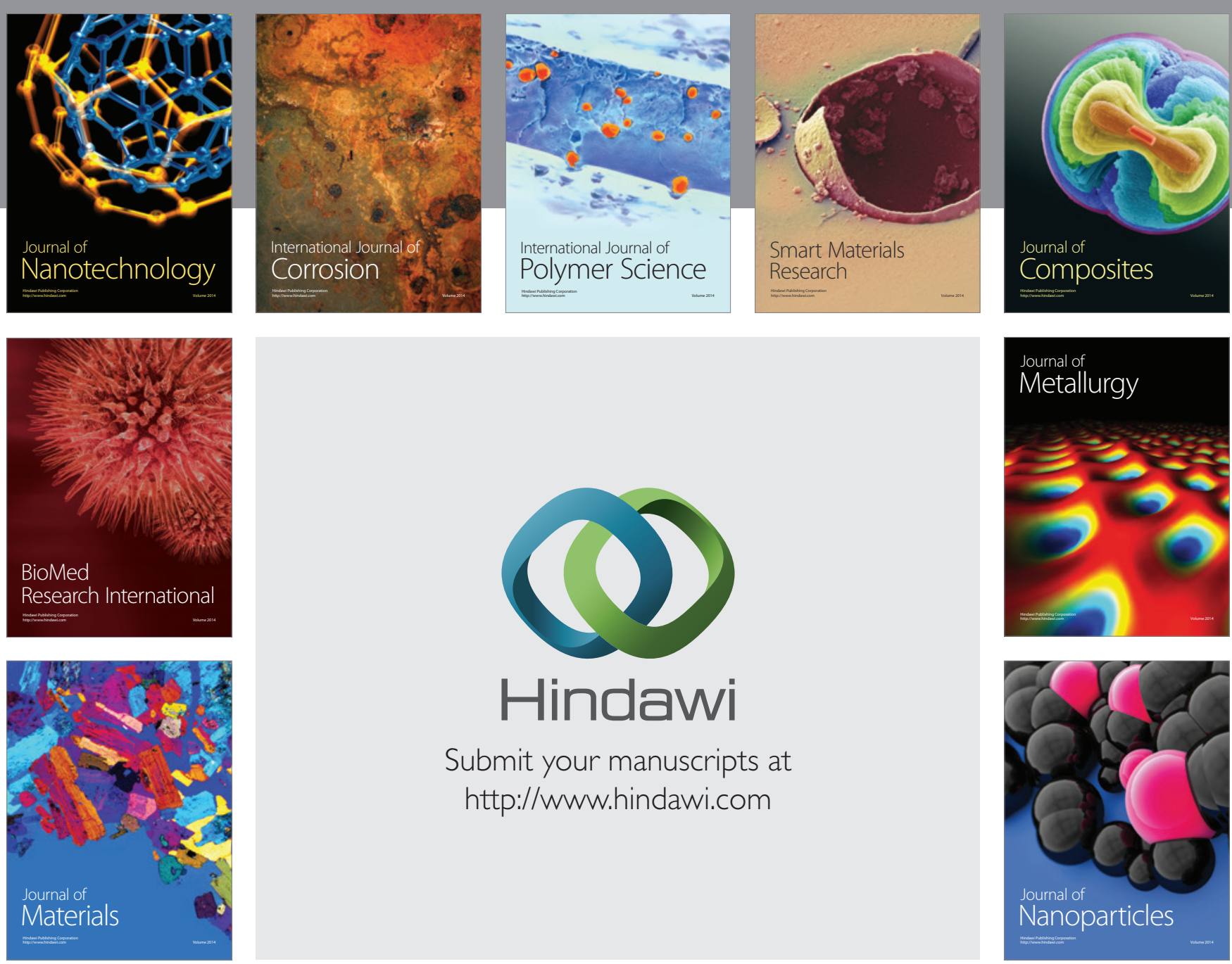

Submit your manuscripts at http://www.hindawi.com
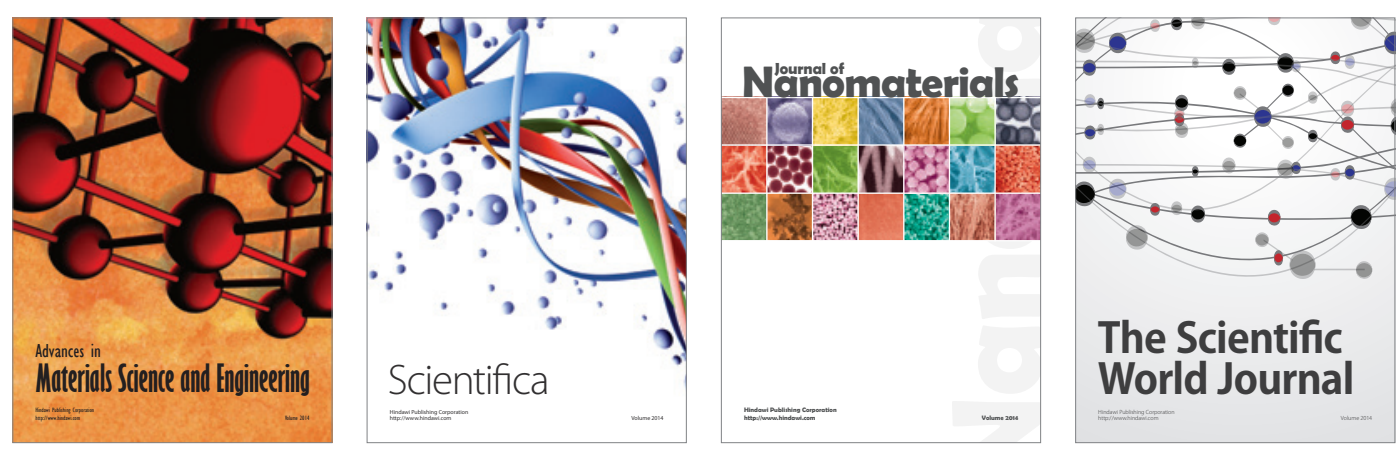

\section{The Scientific World Journal}
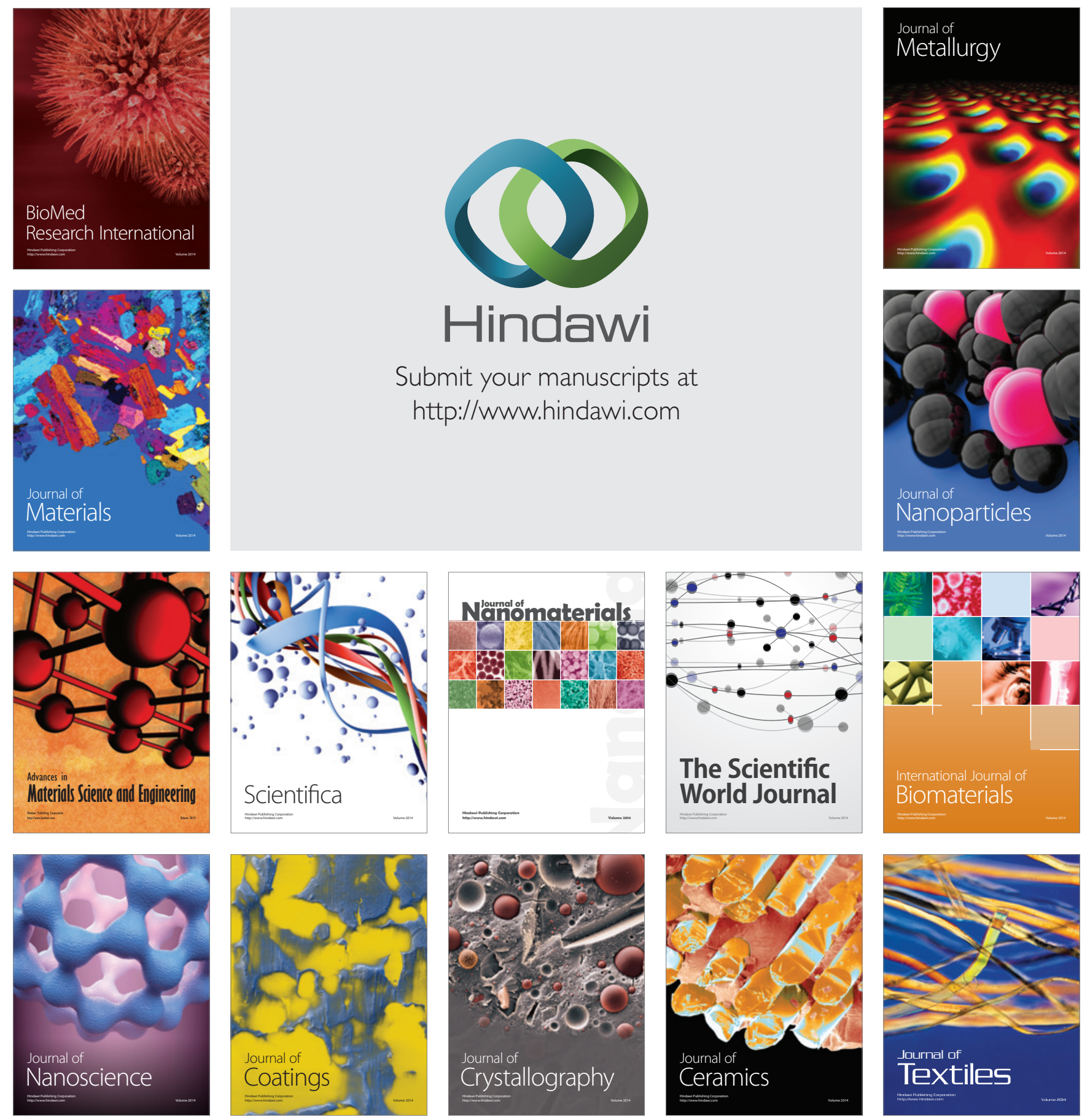